\title{
Data-based assessment of environmental controls on global marine nitrogen fixation
}

\author{
Y.-W. Luo ${ }^{1, *}$, I. D. Lima ${ }^{1}$, D. M. Karl' ${ }^{2}$, C. A. Deutsch ${ }^{3}$, and S. C. Doney ${ }^{1}$ \\ ${ }^{1}$ Department of Marine Chemistry and Geochemistry, Woods Hole Oceanographic Institution, Woods Hole, \\ Massachusetts, USA \\ ${ }^{2}$ Center for Microbial Oceanography: Research and Education, University of Hawaii, Honolulu, Hawaii, USA \\ ${ }^{3}$ School of Oceanography, University of Washington, Seattle, Washington, USA \\ * current address: State Key Laboratory of Marine Environmental Science, Xiamen University, Xiamen, China
}

Correspondence to: Y.-W. Luo (ywluo@xmu.edu.cn)

Received: 2 April 2013 - Published in Biogeosciences Discuss.: 29 April 2013

Revised: 2 January 2014 - Accepted: 3 January 2014 - Published: 6 February 2014

\begin{abstract}
There are a number of hypotheses concerning the environmental controls on marine nitrogen fixation (NF). Most of these hypotheses have not been assessed against direct measurements on the global scale. In this study, we use $\sim 500$ depth-integrated field measurements of NF covering the Pacific and Atlantic oceans to test whether the spatial variance of these measurements can be explained by the commonly hypothesized environmental controls, including measurement-based surface solar radiation, mixed layer depth, average solar radiation in the mixed layer, sea surface temperature, wind speed, surface nitrate and phosphate concentrations, surface excess phosphate $\left(\mathrm{P}^{*}\right)$ concentration and subsurface minimum dissolved oxygen (in upper $500 \mathrm{~m}$ ), as well as model-based $\mathrm{P}^{*}$ convergence and atmospheric dust deposition. By conducting simple linear regression and stepwise multiple linear regression (MLR) analyses, surface solar radiation (or sea surface temperature) and subsurface minimum dissolved oxygen are identified as the predictors that explain the most spatial variance in the observed NF data, although it is unclear why the observed NF decreases when the level of subsurface minimum dissolved oxygen is higher than $\sim 150 \mu \mathrm{M}$. Dust deposition and wind speed do not appear to influence the spatial patterns of NF on global scale. The weak correlation between the observed NF and the $\mathrm{P}^{*}$ convergence and concentrations suggests that the available data currently remain insufficient to fully support the hypothesis that spatial variability in denitrification is the principal control on spatial variability in marine NF. By applying the MLR-derived equation, we estimate the global-integrated NF at 74 (error
\end{abstract}

range 51-110) $\mathrm{Tg} \mathrm{Nyr}^{-1}$ in the open ocean, acknowledging that it could be substantially higher as the ${ }^{15} \mathrm{~N}_{2}$-assimilation method used by most of the field samples underestimates NF. More field NF samples in the Pacific and Indian oceans, particularly in the oxygen minimum zones, are needed to reduce uncertainties in our conclusion.

\section{Introduction}

Nitrogen $(\mathrm{N})$ is one of the most important nutrients for marine ecosystems. Nitrogen fixation (NF), a process converting dinitrogen $\left(\mathrm{N}_{2}\right)$ gas into ammonia by bacteria and archaea (collectively termed diazotrophs), is considered to contribute about one half of the total input of bioavailable $\mathrm{N}$ to the contemporary ocean (Galloway et al., 2004; Gruber, 2008).

Marine NF has been hypothesized to be controlled by a number of environmental variables, most of them related to energy and nutrient supply (Carpenter and Capone, 2008; Deutsch et al., 2007; Karl et al., 2002; Sohm et al., 2011). Compared to assimilation of fixed forms of $\mathrm{N}$ such as nitrate and ammonium, NF requires additional cellular energy to split and then reduce the $\mathrm{N}_{2}$ molecule. Thus, light, in supplying sufficient energy to diazotrophs, can be an important factor controlling NF (Karl et al., 2008). It has been shown that the nitrogenase (the enzymes used to fix $\mathrm{N}_{2}$ ) activity of photoautotrophic diazotrophs is closely linked to photosynthesis (Carr and Whitton, 1982; Gallon, 2001; Karl et al., 2008). For this reason, NF generally occurs in surface 
seawaters with strong stratification, shallow mixed layers, and high solar energy fluxes. Enhanced stratification can also limit the resupply of nitrate into surface waters leading to fixed $\mathrm{N}$ stress and selection for diazotrophs. High temperature can also stimulate nitrogenase activity (Staal et al., 2003). Our current paradigm of the roles of light and temperature is supported by the fact that diazotrophs, especially Trichodesmium, are often found in warm marine habitats (Carpenter, 1983a, b; Carpenter and Capone, 1992), where solar energy fluxes are high and stratification is often strong. This paradigm leads to another hypothesis that high wind speed can be negative factor for marine NF, as it may cause destratification, surface cooling, and a resupply of nitrate. Note that marine NF by heterotrophic organisms might also be important (Halm et al., 2012) and does not directly rely on solar radiation; although the controlling mechanisms for aphotic NF are unclear, they must rely on an adequate supply of energy.

Iron $(\mathrm{Fe})$ and phosphorus $(\mathrm{P})$ are two major nutrients hypothesized to limit marine NF. Fe is an important cofactor for nitrogenase (Howard and Rees, 1996), and NF requires 5-10 times more Fe than that for ammonium assimilation (Berman-Frank et al., 2001; Kustka et al., 2003). As diazotrophs are not limited by $\mathrm{N}$ supply, $\mathrm{P}$ is inevitably another major requirement by diazotrophs. In the Atlantic Ocean, NF was reported to be limited by Fe (Fernández et al., 2010; Moore et al., 2009), by P (Sañudo-Wilhelmy et al., 2001), or co-limited by both Fe and P (Mills et al., 2004). NF in the Pacific was also reported to be controlled by Fe (Dutkiewicz et al., 2012; Watkins-Brandt et al., 2011) or P (Karl et al., 2001; Karl et al., 1997) - findings which, however, were not supported by some other studies (Grabowski et al., 2008; Moutin et al., 2008).

$\mathrm{NF}$ may also be triggered by loss of bioavailable $\mathrm{N}$, which normally occurs in subsurface oxygen minimum zones (OMZs) through denitrification (Lam and Kuypers, 2011). A low ratio of fixed $\mathrm{N}$ to $\mathrm{P}(<16: 1)$ in supply to the surface layer may lead to a selection for diazotrophs (Karl and Letelier, 2008). N-deficient waters can be identified by $\mathrm{P}^{*}=\mathrm{P}-\mathrm{N} / r_{n}$, the excess fixed $\mathrm{P}$ relative to fixed $\mathrm{N}$, where $r_{n} \approx 16$ is the typical $\mathrm{N}: \mathrm{P}$ stoichiometry for phytoplankton biomass (Deutsch et al., 2007). Note that the $\mathrm{P}^{*}$ signal can be both a driver and a responder to marine NF: N-deficient, high-P* waters generated in subsurface layers, when brought to surface, may stimulate NF therein, which may in turn reduce the $\mathrm{P}^{*}$.

Although these hypothesized environmental controls on marine NF are all plausible and may be important on both cellular and ecosystem scales, most of them have not been validated against direct field measurements on a global scale. In a recent effort, a database termed MAREDAT, with up-todate direct field measurements of plankton functional groups (Buitenhuis et al., 2013), was compiled; it includes more than 500 depth-integrated NF rates with good spatial coverage for the tropical and subtropical Pacific and Atlantic oceans (Luo et al., 2012). Many of these previous measurements may have significantly underestimated $\mathrm{NF}$, as the ${ }^{15} \mathrm{~N}_{2}$ gas used to estimate in vitro rates of NF probably does not attain equilibrium with surrounding water during a typical $12-24 \mathrm{~h}$ incubation period (Mohr et al., 2010). Two case studies showed that previous methods may have underestimated NF on average by $\sim 40 \%$ (Großkopf et al., 2012) and $\sim 60 \%$ (Wilson et al., 2012). However, we believe that the previous measurements can still be used to reveal spatial patterns of ocean NF. In addition, our oceanic data set represents a log-normal distribution of rates over $\sim 6$ orders of magnitude (Luo et al., 2012), so uncertainties of 40-60\% in measurement accuracy is probably not a first-order concern in our study. In this study, we use simple linear regression and multiple linear regression (MLR) of log-transformed NF field observations to assess whether and to what degree observed spatial patterns of NF in the Pacific and Atlantic oceans are consistent with existing hypotheses for the environmental controls on NF. We further diagnose a global ocean NF rate based on the resulting MLR equation, and propose how major environmental controls on NF operate in different ocean regions.

\section{Methods}

\subsection{Data sources}

NF and 11 environmental parameters were used in the regression analyses of this study (Table 1). A total 642 depthintegrated NF rates were retrieved from the MAREDAT diazotrophic database (Luo et al., 2012) stored in the data repository PANGAEA (doi:10.1594/PANGAEA.774851). It is noted that integration depths varied between the observational studies incorporated into this original data set. We only used 534 data points in the open ocean with ocean floor deeper than $250 \mathrm{~m}$. None of these open-ocean samples were in the Indian Ocean, as the seven only data points in the Indian Ocean were all collected in shallow coastal regions. The rates were approximately log-normally distributed (Fig. 1a and b); thus in this study we used base-10 logarithms of these rates (practically trimming 5 zero-value data points). Most rates (490 data points) were measured using the ${ }^{15} \mathrm{~N}_{2}$ assimilation method, and the others were based on $\mathrm{C}_{2} \mathrm{H}_{2}$ reduction. The ${ }^{15} \mathrm{~N}_{2}$ assimilation method does not count the newly fixed $\mathrm{N}$ released by diazotrophs in dissolved forms, and may result in lower NF than those measured by the $\mathrm{C}_{2} \mathrm{H}_{2}$ reduction method (Mulholland, 2007; Mulholland et al., 2004). We included data measured by both methods in our analysis because the bias is reasonably low in log space. Furthermore, exclusion of $\mathrm{NF}$ rates by $\mathrm{C}_{2} \mathrm{H}_{2}$ reduction would have resulted in large data voids for regions of the equatorial Pacific and subtropical Atlantic.

Environmental parameters used in our regression analyses included surface solar radiation, mixed layer depth, average solar radiation in the mixed layer, sea surface 

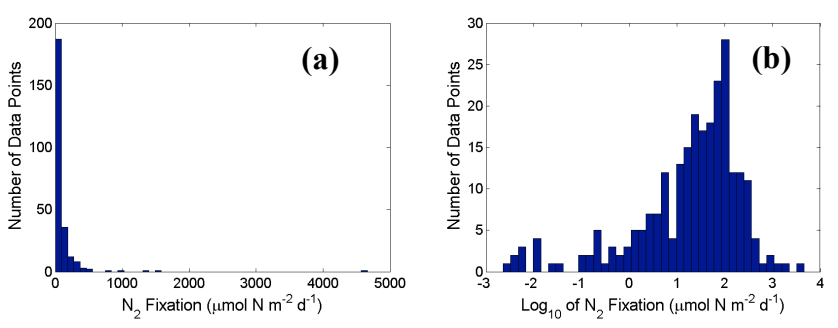

(c)

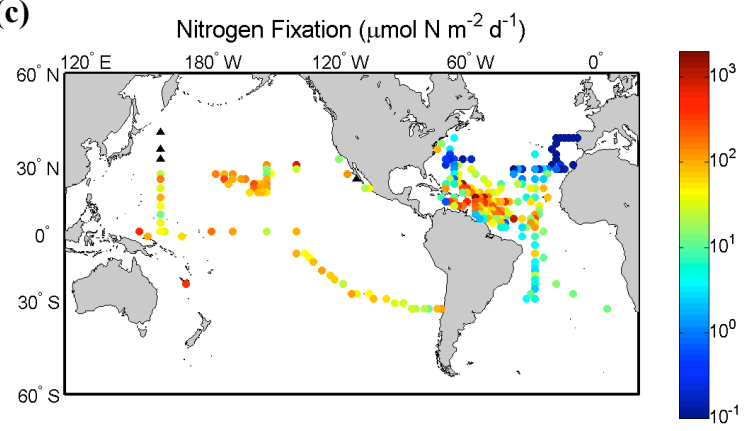

Fig. 1. Histogram of open-ocean nitrogen fixation measurements on (a) linear and (b) logarithmic scales. (c) The nitrogen fixation measurements in the Pacific and Atlantic oceans binned on $2^{\circ} \times 2^{\circ}$ grids, with black triangles representing zero nitrogen fixation rates (reported below detection limits).

temperature (SST) $(0-25 \mathrm{~m})$, surface nitrate and phosphate concentration ( $0-25 \mathrm{~m})$, atmospheric dust deposition (representing $\mathrm{Fe}$ deposition), minimum dissolved oxygen in the upper $500 \mathrm{~m}$, surface wind speed, surface excess phosphate $\left(\mathrm{P}^{*}=\right.$ phosphate - nitrate $\left./ 16\right)$ and $\mathrm{NF}$ diagnosed from $\mathrm{P}^{*}$ convergence integrated from $0-125 \mathrm{~m}$ (Table 1). Only the concentrations of nitrate and phosphate were used in this study because of data availability, although we acknowledge that their fluxes can be better variables in assessing the impacts on marine NF. For instance, a nutrient with low concentration but high supply fluxes (i.e., high turnover time) may not necessarily limit phytoplankton growth. Correlation between nutrient concentration and phytoplankton biomass can even change inversely during different phases of a phytoplankton bloom (Cullen, 1991).

Solar radiation and wind speed data were from the NCEP reanalysis climatology (http://www.esrl.noaa.gov/) (Kalnay et al., 1996). The nitrate, phosphate (Garcia et al., 2010b), dissolved oxygen (Garcia et al., 2010a), and temperature data (Locarnini et al., 2010) were adopted from the World Ocean Atlas 2009 (http://www.nodc.noaa.gov/). At each location, the minimum dissolved oxygen in upper $500 \mathrm{~m}$ was used for that location. The mixed layer depth data were downloaded from IFREMER (http://www.locean-ipsl.upmc.fr/ clement/ mld.html), in which $\sim 50 \mathrm{yr}$ of in situ measurements of temperature and salinity from NODC (National Oceanographic Data Center), WOCE (World Ocean Circulation Experiment) and Argo floats programs were used to construct density pro- files, and the mixed layer depth was estimated as the depth where the potential density was $0.03 \mathrm{~kg} \mathrm{~m}^{-3}$ higher than at the surface (de Boyer Montégut et al., 2004). It is noted that this criterion for diagnosing the mixed layer depth using density profiles reflects the past mixing, but may not always be a good estimate for the present strength of turbulence. Diazotrophs in the presently estimated mixed layer may not be fully mixed on short time scale. Average solar radiation in the mixed layer is derived from surface solar radiation and mixed layer depth, assuming solar radiation attenuates exponentially through water column with attenuation coefficient $K_{\mathrm{PAR}}=0.045 \mathrm{~m}^{-1}$ (thus solar radiation decreases to $1 \%$ of its surface value at $100 \mathrm{~m}$ ). To test sensitivity of the analysis for using this constant attenuation coefficient, climatological SeaWiFS (Sea-viewing Wide Field-ofview Sensor) near-surface chlorophyll concentrations "Chl" (in $\mathrm{mg} \mathrm{m}^{-3}$ ) (http://oceancolor.gsfc.nasa.gov/) and an empirical form (Morel, 1988) were also used to produce spatially variable attenuation coefficient (in $\mathrm{m}^{-1}$ ):

$K_{\text {PAR }}=0.121 \mathrm{Chl}^{0.428}$.

For the rate of atmospheric dust deposition, we used the same product as in the Community Climate System Model (CCSM-3) (Doney et al., 2009): simulation of a threedimensional atmospheric chemical transport model which has been well validated by in situ measurements (Luo et al., 2003; Mahowald et al., 2003). The diagnosed marine NF $\left(J_{\mathrm{NF}}\right)$ from the convergence of $\mathrm{P}^{*}$ used in this study was the product from Deutsch et al. (2007), considering both inorganic and organic $\mathrm{N}$ and $\mathrm{P}$. Although $J_{\mathrm{NF}}$ was a product of NF rates, it was treated in our study as an independent environmental parameter. $J_{\mathrm{NF}}$ also relies on several other variables used in its diagnosis, including the $\mathrm{N}: \mathrm{P}$ ratios of non$\mathrm{N}_{2}$-fixing and $\mathrm{N}_{2}$-fixing phytoplankton and particle export ratio. However, the $\mathrm{N}: \mathrm{P}$ ratio of marine organic matter has recently been found to exhibit large spatial variations (Martiny et al., 2013). For this reason, we used $J_{\mathrm{NF}}$ only in the simple linear regression to test its correlation with the observed NF; we did not use $J_{\mathrm{NF}}$ in the MLR, however, in order to avoid introducing uncertainties of this variable in estimating global NF. Preliminary results have shown that the apparent $J_{\mathrm{NF}}$ in high latitudes in the results of Deutsch et al. (2007) disappears if the $\mathrm{P}^{*}$ convergence diagnostic model uses N:P ratio of diatom in high latitudes. Thus we only used $J_{\mathrm{NF}}$ between $40^{\circ} \mathrm{S}$ and $40^{\circ} \mathrm{N}$ in this study. The surface concentrations of nitrate, phosphate and $\mathrm{P}^{*}, J_{\mathrm{NF}}$ and atmospheric dust deposition were approximately log-normally distributed, and thus were also log-transformed.

Annual climatologies were used for all the environmental data. They were binned on $2^{\circ} \times 2^{\circ}$ grids as most of them have original spatial resolution better than $2^{\circ}$ (Table 1 ). To match the resolution, the log-transformed NF rates were also binned on $2^{\circ} \times 2^{\circ}$ grids using the mean of data in each bin, resulting in 235 binned vertically integrated NF rates in the Pacific and Atlantic oceans (Fig. 1c). 
Table 1. Data sources of nitrogen fixation and environmental parameters and the simple linear regression results ${ }^{\mathrm{a}}$.

\begin{tabular}{|c|c|c|c|c|c|c|c|}
\hline \multirow[t]{2}{*}{ Data description } & \multirow[t]{2}{*}{ Symbol } & \multirow[t]{2}{*}{ Source } & \multirow{2}{*}{$\begin{array}{l}\text { Spatial } \\
\text { reso- } \\
\text { lution }\end{array}$} & \multirow{2}{*}{$\begin{array}{l}\text { Log-normally } \\
\text { distributed and } \\
\text { log-transformed }\end{array}$} & \multicolumn{3}{|c|}{ Regression to nitrogen fixation } \\
\hline & & & & & $\begin{array}{c}R^{2} \\
\text { (linear) }\end{array}$ & $\begin{array}{l}\text { Slope } \\
\text { (linear) }\end{array}$ & $\begin{array}{c}R^{2} \\
\text { (quadratic) }\end{array}$ \\
\hline Observed nitrogen fixation $\left(\mu \mathrm{mol} \mathrm{N} \mathrm{m}{ }^{-2} \mathrm{~d}^{-1}\right)$ & NF & MAREDAT & & Yes & & & \\
\hline Surface downward solar radiation $\left(\mathrm{W} \mathrm{m}^{-2}\right)$ & $I_{\mathrm{S}}$ & NCEP & $2^{\circ}$ & No & 0.34 & $0.58 \pm 0.05$ & 0.38 \\
\hline Surface wind speed $\left(\mathrm{m} \mathrm{s}^{-1}\right)$ & WIND & Reanalysis & $2.5^{\circ}$ & No & $0.00^{\mathrm{b}}$ & $-0.01 \pm 0.07$ & $0.01^{\mathrm{b}}$ \\
\hline Mixed layer depth (m) & MLD & IFREMER & $2^{\circ}$ & No & 0.19 & $-0.44 \pm 0.06$ & 0.19 \\
\hline Average solar radiation in mixed layer $\left(\mathrm{W} \mathrm{m}^{-2}\right)$ & $I_{\mathrm{ML}}$ & $I_{\mathrm{S}}$ and $\mathrm{MLD}$ & $2^{\circ}$ & No & 0.18 & $0.43 \pm 0.06$ & 0.23 \\
\hline Sea surface temperature $\left({ }^{\circ} \mathrm{C}\right)$ & SST & & $1^{\circ}$ & No & 0.26 & $0.51 \pm 0.06$ & 0.27 \\
\hline Minimum dissolved oxygen in $0-500 \mathrm{~m}(\mu \mathrm{M})$ & $\mathrm{DO}_{\min }$ & World Ocean & $1^{\circ}$ & No & 0.27 & $-0.52 \pm 0.06$ & 0.39 \\
\hline Surface nitrate $(\mu \mathrm{M})$ & DIN & Atlas 2009 & $1^{\circ}$ & Yes & $0.01^{\mathrm{b}}$ & $-0.12 \pm 0.07$ & 0.03 \\
\hline Surface phosphate $(\mu \mathrm{M})$ & DIP & & $1^{\circ}$ & Yes & 0.03 & $0.16 \pm 0.06$ & 0.03 \\
\hline Excess phosphate $(\mu \mathrm{M})$ & $\mathrm{P}^{*}$ & DIP-DIN / 16 & $1^{\circ}$ & Yes & 0.07 & $0.26 \pm 0.06$ & 0.07 \\
\hline Surface dust deposition $\left(\mathrm{mg} \mathrm{m}^{-2} \mathrm{~d}^{-1}\right)$ & DST & Model & $2^{\circ}$ & Yes & $0.00^{\mathrm{b}}$ & $-0.04 \pm 0.07$ & 0.16 \\
\hline $\begin{array}{l}\text { Nitrogen fixation estimated from } \mathrm{P}^{*} \text { convergence } \\
\left(\mu \mathrm{mol} \mathrm{N} \mathrm{m}^{-2} \mathrm{~d}^{-1}\right)\end{array}$ & $J_{\mathrm{NF}}$ & Model & $2^{\circ}$ & Yes & 0.07 & $0.27 \pm 0.07$ & 0.11 \\
\hline
\end{tabular}

${ }^{a}$ Regression results are for standardized log-transformed nitrogen fixation rate versus each standardized environmental parameter, including $R^{2}$ and slope ( \pm one standard error) when only linear, 1st-degree terms were used, and $R^{2}$ when quadratic, 2nd-degree terms are added. Note that DIN, DIP, $\mathrm{P}^{*}$, DST and $J_{\mathrm{NF}}$ were also log-transformed before standardization.

${ }^{\mathrm{b}}$ Regression model statistically does not fit the data well, with $p$ value of $F$ test larger than 0.05 .

\subsection{Regression analyses}

All the regressions used in this study utilized least squares methods. Simple linear regressions were conducted for logtransformed NF against each environmental parameter. Before being applied to the regression, data were first standardized to their $z$ scores (Glover et al., 2011):

$z=\frac{x-\bar{x}}{\sigma}$

where $x$ is samples of log-transformed NF or an environmental parameter among which, again, surface nitrate, phosphate and $\mathrm{P}^{*}$ and dust deposition were also log-transformed; $\bar{x}$ and $\sigma$ are the mean and the standard deviation of $x$, respectively. We use $\mathrm{NF}_{z}$ to represent the standardized log-transformed NF hereafter. $R$-squared $\left(R^{2}\right)$ values were calculated for each linear regression to estimate the percentage of the variance in $\mathrm{NF}_{z}$ that can be explained by each environmental parameter. We first tested regressions using only the linear, first-degree term of each environmental parameter in the regression, and then added a second-degree term (i.e., quadratic) to the regression equation.

Stepwise multiple linear regression (MLR) analysis was conducted to establish a statistical model between $\mathrm{NF}_{z}$ and multiple standardized environmental parameters. Both firstdegree and second-degree terms of all the environmental parameters were included as predictor candidates for the MLR. A stepwise procedure (Draper and Smith, 1998) iteratively added or removed predictors from the MLR model using a sequence of $F$ tests of the change in the sum of squared errors: using $p$ value $\leq 0.05$ as a criterion to add new predictors to the model (in ascending order of $p$ ), which statistically could improve the model fit to the data; and using $p \geq 0.10$ as a criterion to remove predictors from the existing model (in descending order of $p$ ), which statistically would not deteriorate the model fit.

The final MLR equation for the fitted $\mathrm{NF}_{z}$ was

$$
\mathrm{NF}_{z}=\alpha+\sum \beta_{i} z_{i}+\sum \gamma_{j} z_{j}^{2}
$$

where $\alpha$, is the intercept (constant term); $\sum \beta_{i} z_{i}$ is the sum of first-degree terms, with $z_{i}$ representing first-degree predictors in the MLR model and $\beta_{i}$ the corresponding coefficients; similarly, $\sum \gamma_{j} z_{j}^{2}$ is the sum of the second-degree terms for the MLR predictors $z_{j}$ with coefficients $\gamma_{j}$. Cook's distance (Cook, 1977), which measures the effect of deleting an observation from the regression, was used to identify outliers to the MLR (see supplementary material). The MLR was redone after removing outliers.

We also corrected the MLR results for unreasonable terms. The last two terms in Eq. (3) were decomposed into component equations for each environmental parameter $k$ :

$\mathrm{NF}_{z, k}=\left[\beta_{k} z_{k}\right]+\left[\gamma_{k} z_{k}^{2}\right]$,

where the square brackets represent that the terms inside the brackets are included only when they were included in the MLR model. If the relation between $\mathrm{NF}_{z, k}$ and $z_{k}$ contradicted the hypothesized direction, we noted this discrepancy, excluded that environmental parameter, and redid the MLR analysis. When $\mathrm{NF}_{z, k}$ included a second-degree term and thus the relation between $\mathrm{NF}_{z, k}$ and $z_{k}$ is not monotonic, we 
identified whether $\mathrm{NF}_{z, k}$ mainly increased or decreased with $z_{k}$ over the whole range of $z_{k}$.

\subsection{Diagnostic estimate of global nitrogen fixation}

The obtained MLR Eq. (3) was used to diagnose NF in the global ocean. To be consistent with the MLR coefficient values, the global maps of environmental parameters were transformed to $z$ scores using the values of mean and standard deviation found in Eq. (2) for the NF sampling locations.

In building the MLR equation, we assumed implicitly that the field data sampled NF under all the possible environmental conditions. In computing global maps we therefore needed to bound the spatial region over which the regression was valid, allowing for no extrapolation outside the domain in parameter space constrained by the regression. In the locations where NF has been observed, we calculated lower (upper) bounds for properties that correlated positively (negatively) with NF. These levels were then used as the lower (upper) limits for effective NF when estimating global NF using the MLR equation. In any location where the value of any environmental parameter included in the MLR model fell outside the limits, the estimated NF was assumed to be zero. We also limited the maximum estimated NF to the highest observed level.

For the MLR component $\mathrm{NF}_{z, k}$ from each environmental parameter $k$, the spatial anomaly in the global ocean was then used to study whether that environmental parameter favored or limited NF in different ocean regions.

\subsection{Error propagation}

For a MLR equation, considering the predicted variable as the function of the coefficients $y=f\left(a_{1}, a_{2}, \ldots, a_{n}\right)$, the error for $y, \sigma_{y}$, is propagated from the covariance of the coefficients (Glover et al., 2011):

$\sigma_{y}^{2}=\sum_{i=1}^{n} \sum_{j=1}^{n} \sigma_{i j}^{2}\left(\frac{\partial f}{\partial a_{i}}\right)\left(\frac{\partial f}{\partial a_{j}}\right)$,

where $\sigma_{i j}^{2}$ is the covariance between coefficients $i$ and $j$. Note that the covariance between a coefficient and itself, $\sigma_{i i}^{2}$, equals the squared error of the coefficient. Applying Eq. (5) to a MLR component Eq. (4) (if both first- and second-degree terms were included) estimates the error for $\mathrm{NF}_{z, k}$ resulting from an environment parameter $k$ as

$\sigma_{\mathrm{NF}_{z, k}}=\sqrt{\sigma_{\beta, k}^{2} z_{k}^{2}+\sigma_{\gamma, k}^{2} z_{k}^{4}+2 \sigma_{\beta \gamma, k}^{2} z_{k}^{3}}$,

where $\sigma_{\beta, k}$ and $\sigma_{\gamma, k}$ are the standard error for coefficients $\beta_{k}$ and $\gamma_{k}$, respectively; $\sigma_{\beta \gamma, k}^{2}$ is the covariance between $\beta_{k}$ and $\gamma_{k}$. Similarly, Eq. (5) was applied to the full MLR Eq. (3) to estimate the error of the fitted NF as a function of covariance of the MLR coefficients and values of environmental parameters, which were then used to estimate errors in the global estimate of NF.

\section{Results}

\subsection{Spatial variance of nitrogen fixation and environmental parameters}

The binned observations (Fig. 1c) showed different patterns of NF in the Atlantic and Pacific oceans. Observed NF was often high in the tropical Atlantic, reaching levels on the order of $1000 \mu \mathrm{mol} \mathrm{N} \mathrm{m}{ }^{-2} \mathrm{~d}^{-1}$ in the western region. In the subtropical Atlantic, the observed NF was very low, generally on the order of $1 \mu \mathrm{mol} \mathrm{N} \mathrm{m}{ }^{-2} \mathrm{~d}^{-1}$ or less. Although the coverage of the Pacific was not as good as that of the Atlantic, the observed NF in the Pacific varied less and was mostly on the order of $10-100 \mu \mathrm{mol} \mathrm{N} \mathrm{m}{ }^{-2} \mathrm{~d}^{-1}-$ substantially higher than that found in the subtropical Atlantic.

Most physical environmental parameters showed typical spatial patterns (Fig. 2). Subsurface minimum dissolved oxygen $(<500 \mathrm{~m})$ was low in the eastern and northern Pacific and northern Indian Ocean, while in the Atlantic, dissolved oxygen was low only in a small tropical region (Fig. 2e). Dust deposition was highly influenced by continental desert sources, and generally was higher in the Atlantic than in the Pacific (Fig. 2j). $\mathrm{P}^{*}$-convergence predicts high NF in most regions of tropical and subtropical Pacific and in tropical and south subtropical Atlantic, but low NF in north subtropical Atlantic (Fig. 2i). Some of the environmental parameters were highly correlated, especially log-transformed surface phosphate and $\mathrm{P}^{*}(r=0.85)$, as well as surface solar radiation and SST $(r=0.74)$ (Table 2). Average solar radiation in the mixed layer $\left(I_{\mathrm{ML}}\right)$ is highly correlated to the mixed layer depth $(r=-0.91)$ (Table 2), indicating $I_{\mathrm{ML}}$ is mostly determined by the mixed layer depth.

\subsection{Simple linear regression}

Simple linear regressions were conducted between the standardized NF and the standardized individual environmental parameters. When only linear, first-degree terms were allowed for environmental parameters, the $R^{2}$ values (Table 1 ) showed that solar radiation explained the highest percentage $(34 \%)$ of variance in the NF. SST, minimum dissolved oxygen, mixed layer depth and average solar radiation in the mixed layer also explained substantial percentages of NF variance $(26,27,19$, and $18 \%$, respectively). The linear regression models using wind speed, surface nitrate and dust deposition statistically did not fit the observed NF well ( $F$ test, $p=0.85,0.07$, and 0.51 , respectively).

In many cases, the addition of a second-order, quadratic term improved the single-parameter regressions (Table 1). The $R^{2}$ values of the quadratic regressions against solar radiation and minimum dissolved oxygen were the highest $(\sim 0.4)$ among all the regressions. The fitted regression functions predicted that NF increased with solar radiation until reaching a saturated state (Fig. 3a). NF was high above regions with low levels of subsurface minimum dissolved 
(a)

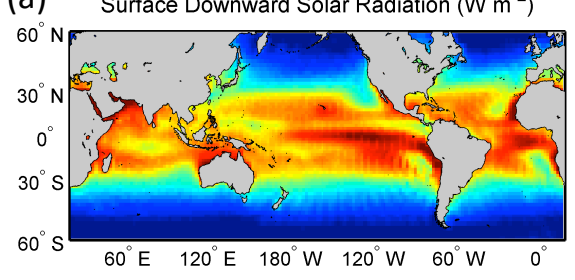

(c) Average Solar Radiation in Mixed Layer $\left(\mathrm{W} \mathrm{m}^{-3}\right)$

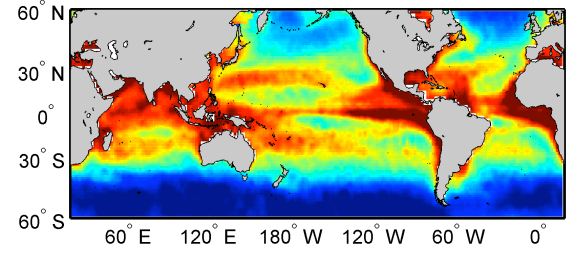

(e) Minimum Dissolved Oxygen in Upper 500m $(\mu \mathrm{M})$

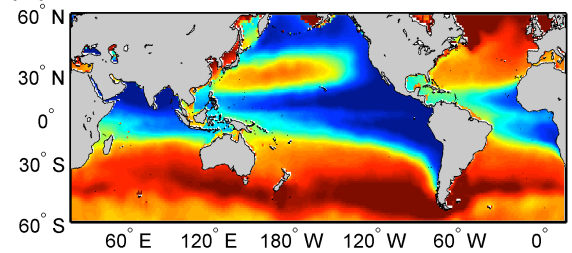

(g) $\mathrm{LOG}_{10}$ of Surface Phosphate Concentration $(\mu \mathrm{M})$

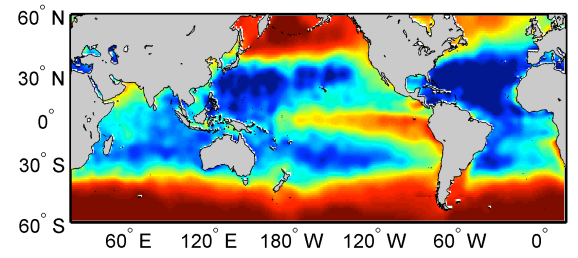

(i) $L O G_{10}$ of $\mathrm{P}^{*}$-convergence $\mathrm{N}_{2}$ Fixation $\left(\mu \mathrm{mol} \mathrm{N} \mathrm{m}{ }^{-2} \mathrm{~d}^{-1}\right)$

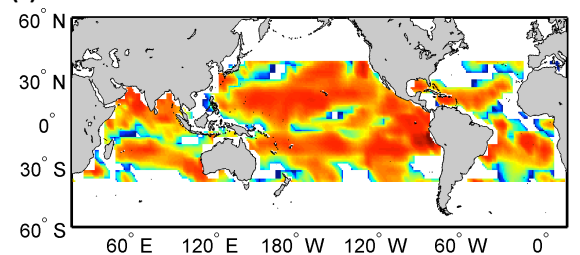

(k)

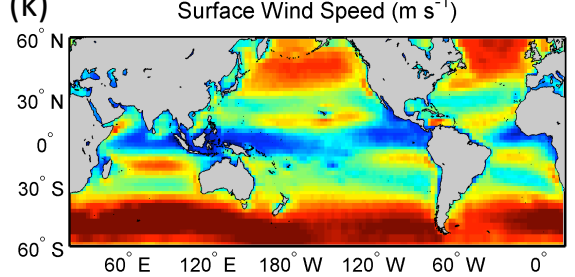

(b)

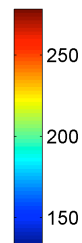
Mixed Layer Depth $(\mathrm{m})$

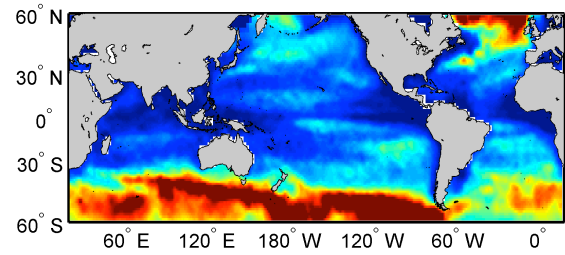

Surface Temperature $\left({ }^{\circ} \mathrm{C}\right)$

(d)

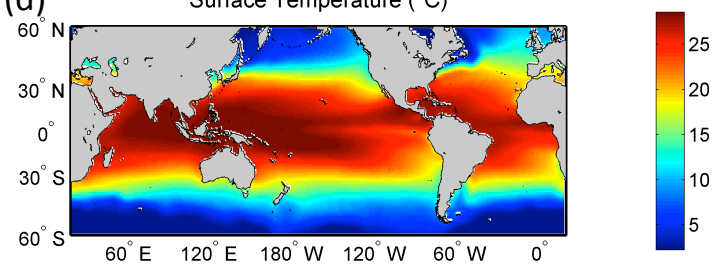

(f) $\quad \mathrm{LOG}_{10}$ of Surface Nitrate Concentration $(\mu \mathrm{M})$
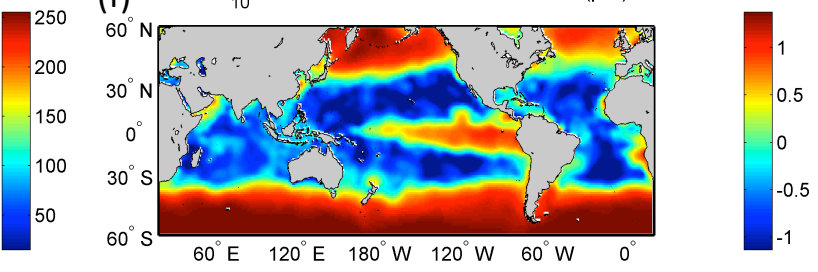

(h) $\mathrm{LOG}_{10}$ of Surface Excess Phosphate $\left(\mathrm{P}^{*}\right)(\mu \mathrm{M})$

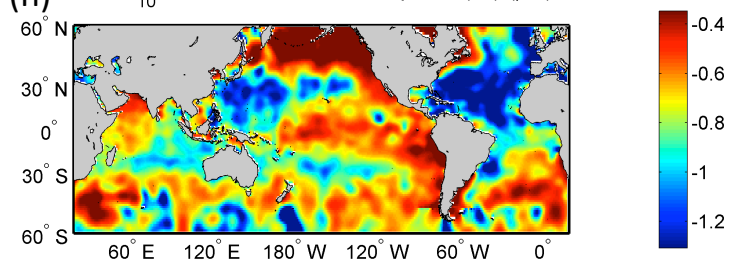

(j) $\mathrm{LOG}_{10}$ of Surface Dust Deposition $\left(\mathrm{mg} \mathrm{m}^{-2} \mathrm{~d}^{-1}\right)$

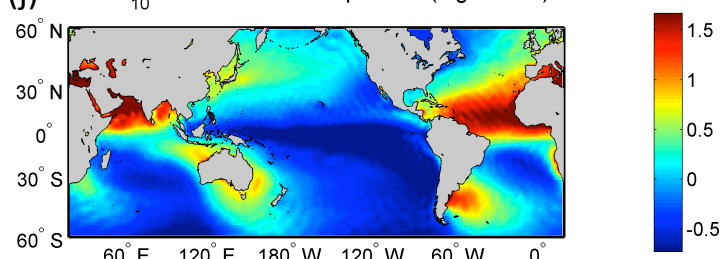

Fig. 2. Maps of environmental parameters in global ocean. Note that nitrate, phosphate, excess phosphate $\left(\mathrm{P}^{*}\right)$ and dust deposition are on $\log _{10}$ scale.

oxygen and started to substantially decrease when minimum dissolved oxygen passed a level of $\sim 150 \mu \mathrm{M}$ (Fig. 3e). NF increased approximately linearly with SST (Fig. 3d). The fitted quadratic function did not predict that NF increased with dust deposition (Fig. 3j), contrary to the hypothesis that $\mathrm{Fe}$ limited NF, assuming the required Fe was mainly supplied by dust deposition. This can actually be expected from a visual inspection of the data: dust deposition was normally lower in 
Table 2. Correlations between environmental parameters at the locations of nitrogen fixation data*

\begin{tabular}{|c|c|c|c|c|c|c|c|c|c|c|}
\hline & SST & MLD & $I_{\mathrm{ML}}$ & $\log _{10}(\mathrm{DIN})$ & $\log _{10}(\mathrm{DIP})$ & $\log _{10}\left(\mathrm{P}^{*}\right)$ & $\log _{10}\left(J_{\mathrm{NF}}\right)$ & $\log _{10}(\mathrm{DST})$ & $\mathrm{DO}_{\min }$ & WIND \\
\hline$I_{\mathrm{S}}$ & 0.74 & -0.42 & 0.54 & 0.02 & 0.21 & 0.21 & 0.30 & 0.05 & -0.55 & -0.05 \\
\hline SST & & -0.59 & 0.54 & 0.13 & 0.05 & 0.03 & 0.21 & 0.19 & -0.50 & -0.14 \\
\hline MLD & & & -0.91 & -0.35 & -0.06 & 0.06 & -0.01 & -0.44 & 0.50 & 0.00 \\
\hline$I_{\mathrm{ML}}$ & & & & 0.29 & 0.13 & 0.05 & 0.02 & 0.38 & -0.39 & -0.04 \\
\hline $\log _{10}(\mathrm{DIN})$ & & & & & 0.46 & 0.06 & -0.38 & 0.21 & -0.33 & -0.06 \\
\hline $\log _{10}$ (DIP) & & & & & & 0.85 & -0.15 & -0.54 & -0.50 & -0.38 \\
\hline $\log _{10}\left(\mathrm{P}^{*}\right)$ & & & & & & & 0.04 & -0.68 & -0.35 & -0.31 \\
\hline $\log _{10}\left(J_{\mathrm{NF}}\right)$ & & & & & & & & -0.11 & -0.13 & 0.19 \\
\hline $\log _{10}(\mathrm{DST})$ & & & & & & & & & 0.06 & 0.47 \\
\hline $\mathrm{DO}_{\min }$ & & & & & & & & & & 0.10 \\
\hline
\end{tabular}

* See Table 1 for abbreviations of environmental parameters.

the Pacific than in the Atlantic (Fig. 2j), while the observed NF in most regions of the Pacific was much higher than that found in the subtropical Atlantic (Figs. 1c and 3j). Regionally within the North Atlantic, NF does appear to increase with dust deposition in the field data.

Errors can be introduced in the above regression analyses, as a constant light attenuation coefficient was used to derive average solar radiation in the mixed layer. When a variable light attenuation coefficient field derived from SeaWiFS chlorophyll concentration (Eq. 1) was used, even lower $R^{2}$ values, 0.10 and 0.13 , were obtained in the linear and quadratic regression models, respectively. As only nearsurface chlorophyll concentration is provided by the SeaWiFS, and chlorophyll may not actually be fully mixed in the mixed layer on short time scale, three-dimensional chlorophyll fields, such as from models, may improve the $R^{2}$ values. The average solar radiation derived from variable attenuation has a weaker correlation $(-0.84)$ to the mixed layer depth than that derived from constant attenuation $(-0.91)$ (Table 2). Thus the reduced $R^{2}$ values using variable light attenuation suggest that the mixed layer depth, as a proxy for turbulence, may be more important for the NF than the effect of light shading from phytoplankton pigments.

\subsection{Multiple linear regression}

When the first- and second-degree terms of all the environmental parameters are included as predictor candidates for the MLR, the resulting equation components predicted that NF should increase with the surface wind speed and decrease with dust deposition over $\sim 70 \%$ of the dust deposition range; both of these predictions were contrary to the hypothesized relations (Table 3). We thus excluded these two parameters from the predictor candidates. Further, one NF observation was identified as an outlier and excluded from the MLR, as it had a Cook's distance of 0.19 while all the others had values less than 0.08 (Fig. S1 in the supplementary material).
The final MLR model had an $R^{2}$ of 0.59 , explaining $59 \%$ of spatial variance in the observed NF (Table 3). The stepwise MLR (Table 4) first added the linear, first-degree term for surface solar radiation, which alone explained $34 \%$ of the variance for the observed NF. The stepwise MLR then added the first- and the second-degree terms of minimum dissolved oxygen to the regression equation, increasing the $R^{2}$ value by 0.13 and thus explaining $47 \%$ of the total variance in the observed NF. The stepwise MLR then sequentially added the first-degree term for nitrate, the first-degree term for average solar radiation in the mixed layer, the first-degree terms for $\mathrm{P}^{*}$, and the second-degree term for solar radiation, with each additional term increasing the explainable variance by a $\sim 2-4 \%$. The coefficients of the MLR equation, as well as the mean and standard deviation values used to standardize the data to $z$ scores, are listed in Table 5 .

Average solar radiation in the mixed layer, nitrate and $\mathrm{P}^{*}$ contributed to the variation in the fitted NF $\left(\log _{10^{-}}\right.$ transformed) by $\sim 1 z$ score, while minimum dissolved oxygen and solar radiation contributed by $\sim 1.5 z$ scores (Fig. 4). Note that as the standard deviation of the $\log _{10^{-}}$ transformed NF data is 1.1 (Table 5), one unit of change in the $z$ score roughly equals one order of magnitude change in the fitted NF rate. The errors associated with the individual components of the MLR were zero at zero $z$ score of the environmental parameters, increased towards larger positive/negative anomalies of the environmental parameters, and could be large where the numbers of samples were limited (Fig. 4 and Eq. 6). Note that when calculating the fitted NF, not its components, the error of intercept and the covariances among coefficients also contributed to the errors (Eq. 5), and thus the errors of the fitted NF were not zero at zero $z$ score of the environmental parameters. The fitted NF monotonically increased with $\mathrm{P}^{*}$ and decreased with mixed layer depth and surface nitrate (Fig. 4 and Table 3). The fitted NF component increased with solar radiation when the latter had a less than zero $z$ score $\left(<\sim 230 \mathrm{~W} \mathrm{~m}^{-2}\right)$ and was approximately constant at higher solar radiation (Fig. 4). The fitted NF component also decreased with minimum dissolved oxygen when 

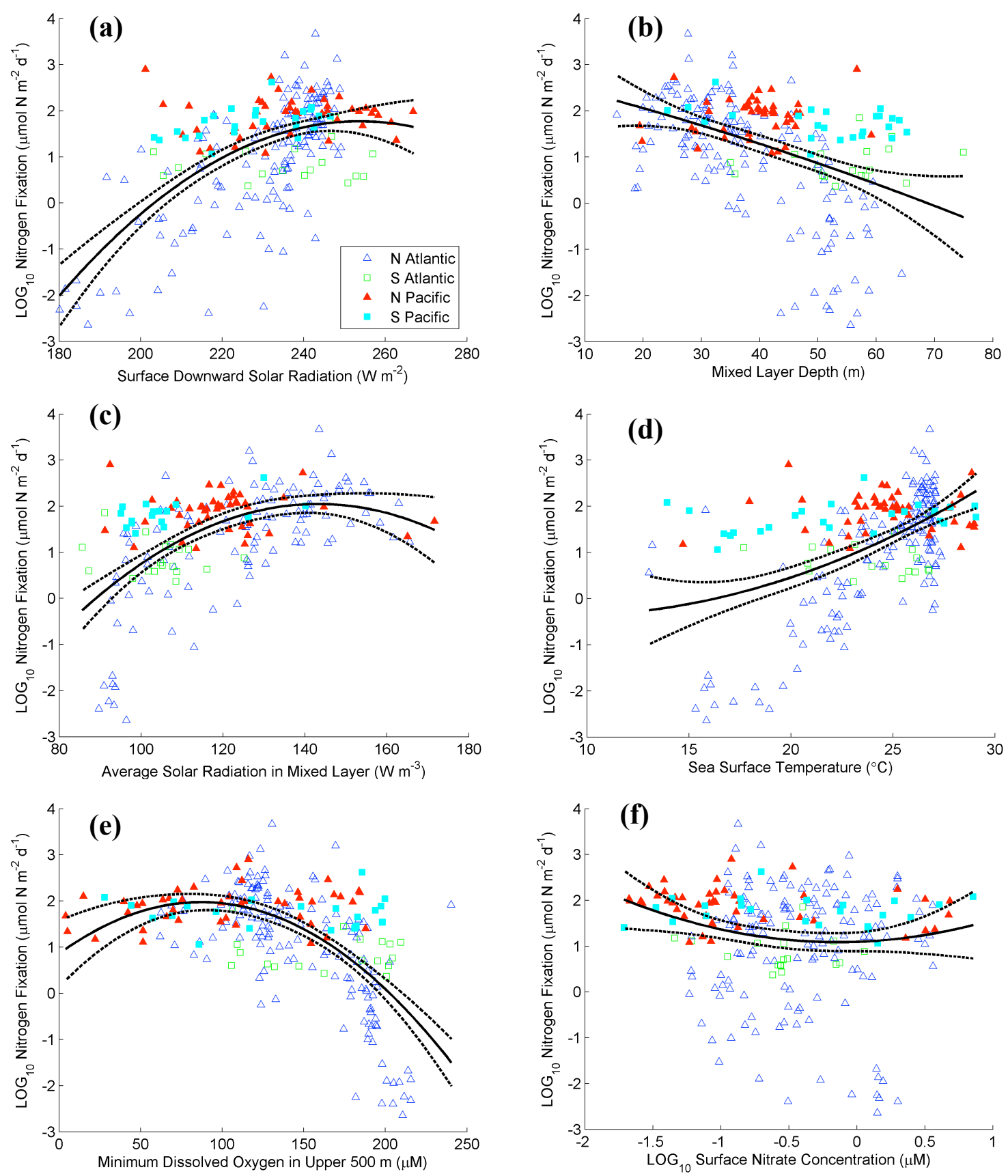

Fig. 3. Quadratic regression (black lines) of log-transformed nitrogen fixation versus each environmental parameters. Note that nitrate, phosphate, excess phosphate $\left(\mathrm{P}^{*}\right)$ and dust deposition are also log-transformed. The dashed lines represent $95 \%$ confidence intervals for the fitted means.

the latter had a higher than $-1 z$ score $(>\sim 90 \mu \mathrm{M})$, stayed at a high level when the minimum dissolved oxygen ranged between $\mathrm{a}-2$ to $-1 z$ score $(\sim 40-90 \mu \mathrm{M})$ (Fig. 4$)$. The fitted NF component slightly decreased when the level of minimum dissolved oxygen was very low $(<-2 z$ scores), but there are only a few samples in this range and the associated errors were large (Fig. 4). Actually, the observed NF seemed to remain at a high level with low minimum dissolved oxygen (Fig. 3e), and thus the slight decrease of the fitted NF at low minimum dissolved oxygen in Fig. 4 was likely generated by the MLR's attempt to achieve a better overall fit, given the influence of other predictors in the MLR.

The MLR-fitted NF reproduced the general pattern of the observed NF on global scale, distributing about a $1: 1$ line 

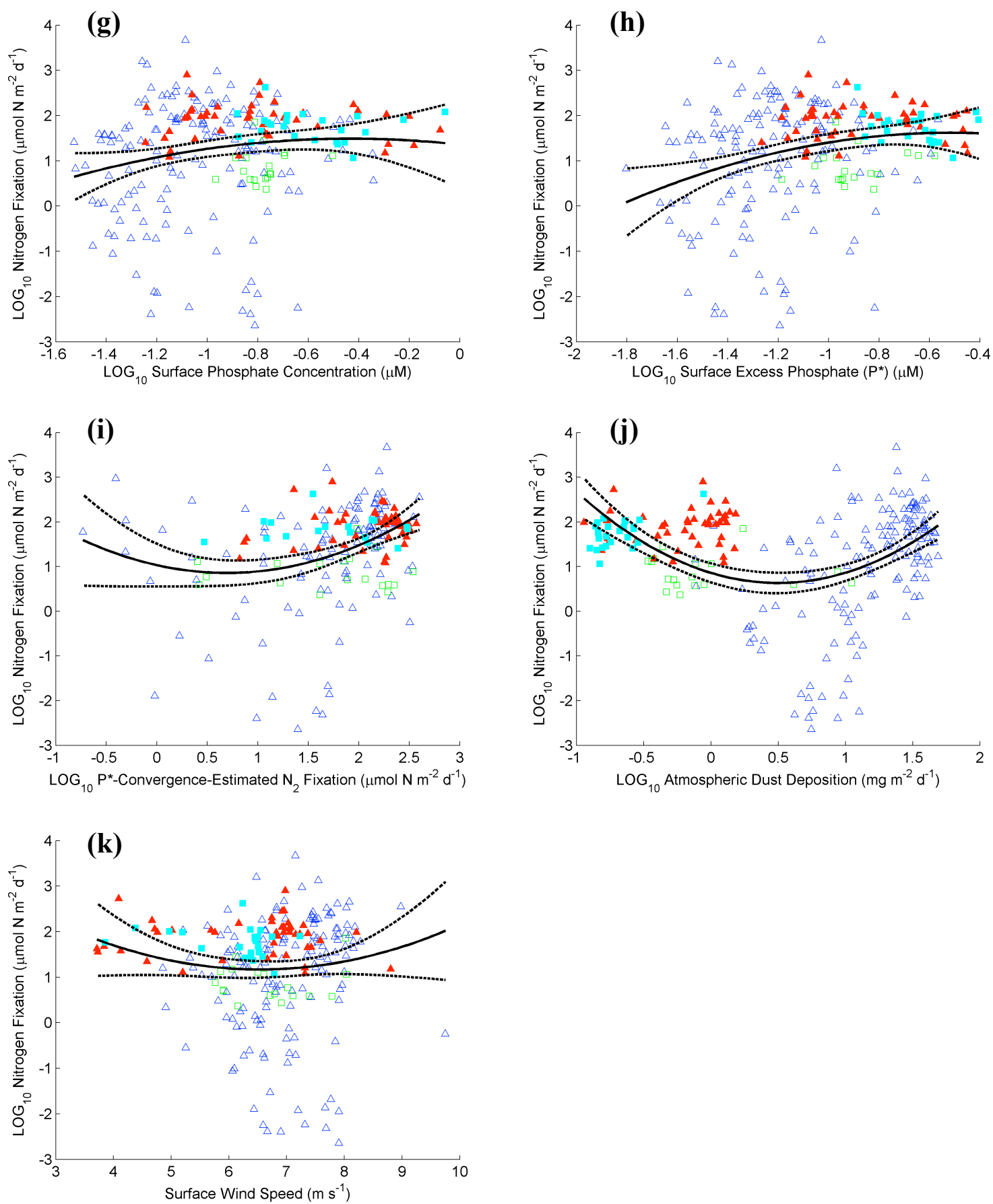

Fig. 3. Continued.

(Fig. 5). Note that the MLR fitted the data from all the basins in one regression. Thus the locations of each basin's fitted data on this overall regression can tell us whether the data in that basin follow the estimated global relationships. The observed NF in the North and South Pacific mostly displayed $z$ scores between 0 and +1 , while the MLR fitted the NF at approximately the correct order of magnitude in the North

Pacific but slightly underestimated the rates in the South Pacific. Both the observed and fitted NF in the South Atlantic mostly had $z$ scores in the range between $\sim 0$ and -1 . The observed NF had the largest range of values in the North Atlantic; their $z$ scores varied from about -3 to +2 . The fitted NF rates in the North Atlantic generally followed the observed pattern, but overestimated the field data when the 
Table 3. Results of stepwise multiple linear regression (MLR) ${ }^{\mathrm{a}}$.

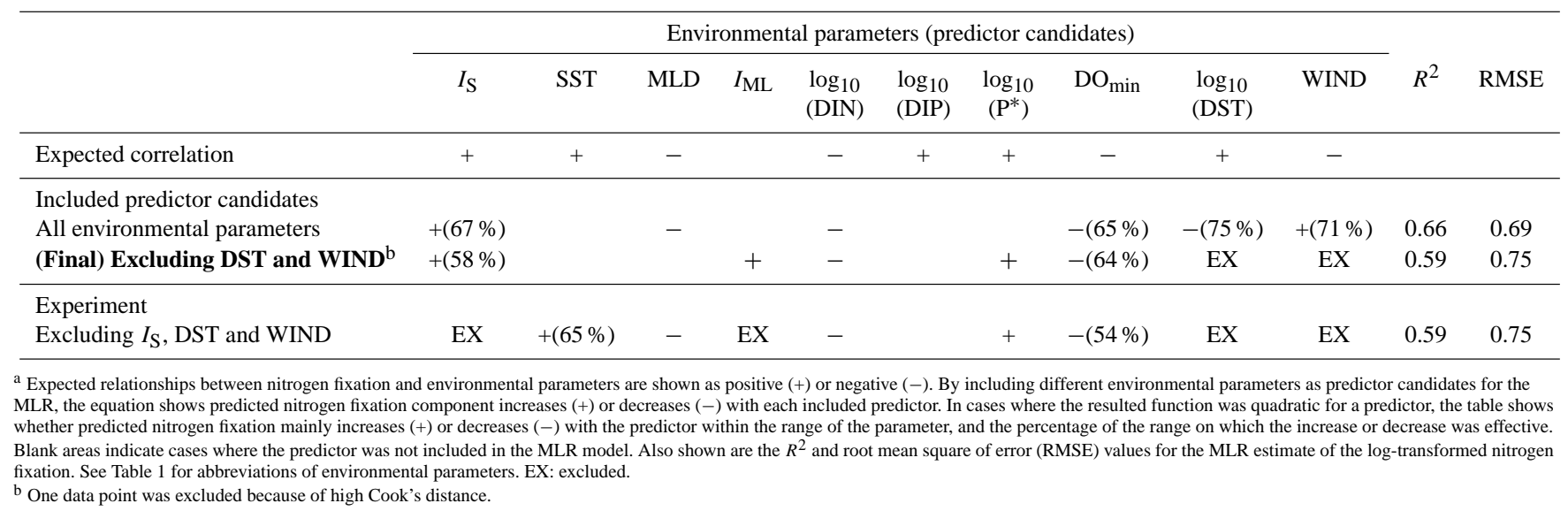

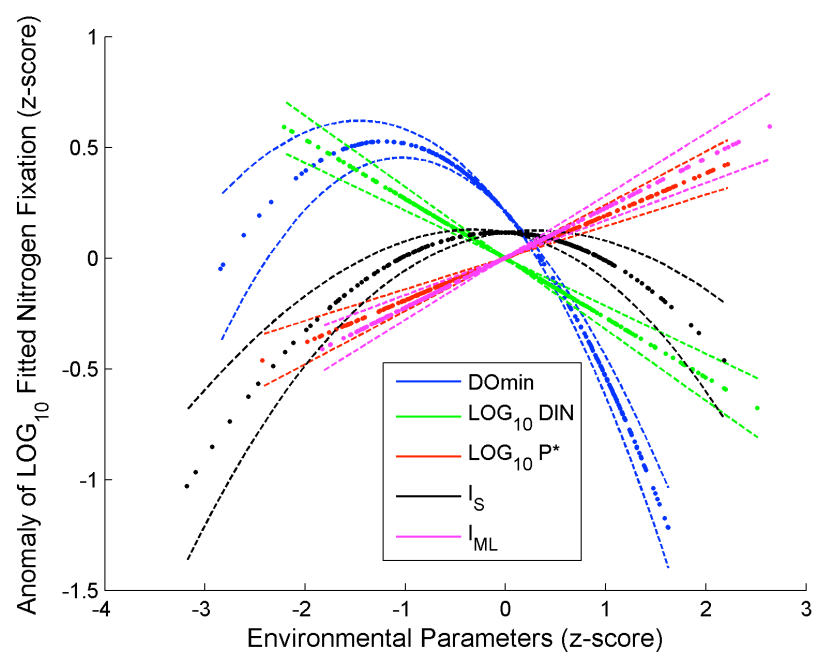

Fig. 4. Final multiple linear regression (MLR) equation, showing functions of fitted log-transformed nitrogen fixation component (anomalies) versus each included predictor, including minimum dissolved oxygen (blue), log-transformed surface nitrate concentration (green) and excess phosphate $\left(\mathrm{P}^{*}\right)(\mathrm{red})$, surface solar radiation $\left(I_{\mathrm{S}}\right)$ (black) and average solar radiation in the mixed layer $\left(I_{\mathrm{ML}}\right)$ (magenta). The dots are locations of observations and the dashed lines represent one standard error for the fitted means in each component function. Results are standardized ( $z$ scores).

observed rates were low and were not able to reproduce several high observed rates.

\subsection{Spatial estimate of nitrogen fixation in global ocean}

The MLR model was used to estimate the global marine NF, with the limits of the environmental parameters and the maximum estimated NF applied (Table 5). The estimated NF (Fig. 6a) reproduced the general patterns observed in the Pacific and Atlantic, with the estimated high NF (on the order of $100 \mu \mathrm{mol} \mathrm{N} \mathrm{m}{ }^{-2} \mathrm{~d}^{-1}$ or higher) spanning latitudinally
Table 4. Stepwise results for the final case of the multiple linear regression (MLR)*.

\begin{tabular}{llll}
\hline Step & Added term & $p$ value & $R^{2}$ \\
\hline 1 & Constant term & & \\
2 & $I_{\mathrm{S}}$ & $1 \times 10^{-22}$ & 0.34 \\
3 & $\mathrm{DO}_{\min }$ & $3 \times 10^{-6}$ & 0.40 \\
4 & $\left(\mathrm{DO}_{\min }\right)^{2}$ & $5 \times 10^{-8}$ & 0.47 \\
5 & $\log _{10}(\mathrm{DIN})$ & $5 \times 10^{-5}$ & 0.51 \\
6 & $I_{\mathrm{ML}}$ & 0.0001 & 0.54 \\
7 & $\log _{10}\left(\mathrm{P}^{*}\right)$ & 0.0002 & 0.57 \\
8 & $\left(\mathrm{I}_{S}\right)^{2}$ & 0.0009 & 0.59 \\
\hline * Dust deposition and surface wind speed were excluded as \\
predictor candidates in this case. The table shows the term \\
added in each step, the $p$ value for the $F$ test for the term \\
addition, and the $R^{2}$ values of the MLR in that step. See \\
Table 1 for abbreviations of environmental parameters.
\end{tabular}

a wider region in the Pacific than in the Atlantic. We also estimated NF for the Indian Ocean, although there are no qualified observations in this basin in the MAREDAT database to be included in the MLR. Thus, practically we assumed that the NF in the Indian Ocean is controlled by the same mechanisms as those in the Pacific and Atlantic, which resulted in high estimated NF in most regions north of $\sim 15^{\circ} \mathrm{S}$ in the Indian Ocean. The environmental parameters limited effective estimated $\mathrm{NF}$ in the range of $\sim 40^{\circ} \mathrm{S}$ to $40^{\circ} \mathrm{N}$ in all the basins. The relative errors of the estimated NF rates were less than $\sim 50 \%$ in most regions (Fig. 6b). An exception was the eastern Pacific, where the errors can be as high as $\sim 150 \%$. The high errors in this region were mostly due to low levels of minimum dissolved oxygen (Fig. 2e) and large uncertainties in the MLR equation when the minimum dissolved oxygen was low (Fig. 4). The total NF in the global ocean was estimated at 74 (error range of mean \pm one standard error: 51-110, same hereafter) $\mathrm{Tg} \mathrm{N} \mathrm{yr}^{-1}$, comprising 14 (9.7-19), 
Table 5. Final multiple linear regression (MLR) results ${ }^{\mathrm{a}}$.

\begin{tabular}{|c|c|c|c|c|c|c|c|}
\hline & & $\begin{array}{l}I_{\mathrm{S}} \\
\left(\mathrm{W} \mathrm{m}^{-2}\right)\end{array}$ & $\begin{array}{l}I_{\mathrm{ML}} \\
\left(\mathrm{W} \mathrm{m}^{-2}\right)\end{array}$ & $\begin{array}{l}\log _{10}(\mathrm{DIN}) \\
(\mu \mathrm{M})\end{array}$ & $\begin{array}{l}\log _{10}\left(\mathrm{P}^{*}\right) \\
(\mu \mathrm{M})\end{array}$ & $\begin{array}{l}\mathrm{DO}_{\min } \\
(\mu \mathrm{M})\end{array}$ & $\begin{array}{l}\log _{10}(\text { Nitrogen } \\
\text { Fixation }) \\
\left(\mu \mathrm{mol} \mathrm{N} \mathrm{m} \mathrm{m}^{-2} \mathrm{~d}^{-1}\right)\end{array}$ \\
\hline $\begin{array}{l}\text { Mean } \pm \text { standard deviation of data } \\
\text { Intercept }\end{array}$ & $0.32 \pm 0.06$ & $232 \pm 16$ & $120 \pm 19$ & $-0.51 \pm 0.54$ & $-1.1 \pm 0.3$ & $139 \pm 47$ & $1.2 \pm 1.1$ \\
\hline $\begin{array}{l}\text { Coefficient of first-degree term in MLR } \\
\text { Coefficient of second-degree term in MLR }\end{array}$ & & $\begin{array}{l}-0.01 \pm 0.07 \\
-0.11 \pm 0.03\end{array}$ & $0.010 \pm 0.003$ & $-0.27 \pm 0.05$ & $0.19 \pm 0.05$ & $\begin{array}{l}-0.53 \pm 0.07 \\
-0.21 \pm 0.04\end{array}$ & \\
\hline Limits $^{b}$ & & $>180 \mathrm{~W} \mathrm{~m}^{-2}$ & $>84 \mathrm{~W} \mathrm{~m}^{-2}$ & $<9.4 \mu \mathrm{M}$ & $>0.016 \mu \mathrm{M}$ & $<240 \mu \mathrm{M}$ & 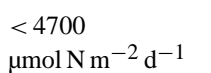 \\
\hline
\end{tabular}

a Mean and standard deviation of the data were used to standardize the data to $z$ scores, which were then used in the MLR. Also shown are coefficients \pm one standard error of the linear first-degree term and, if applicable, of the quadratic second-degree term of each included predictor in MLR. The limits of predictor and maximum allowed nitrogen fixation were also presented. See Table 1 for abbreviations of predictors.

${ }^{\mathrm{b}}$ All numbers are in specified units without $\log$ transformations.

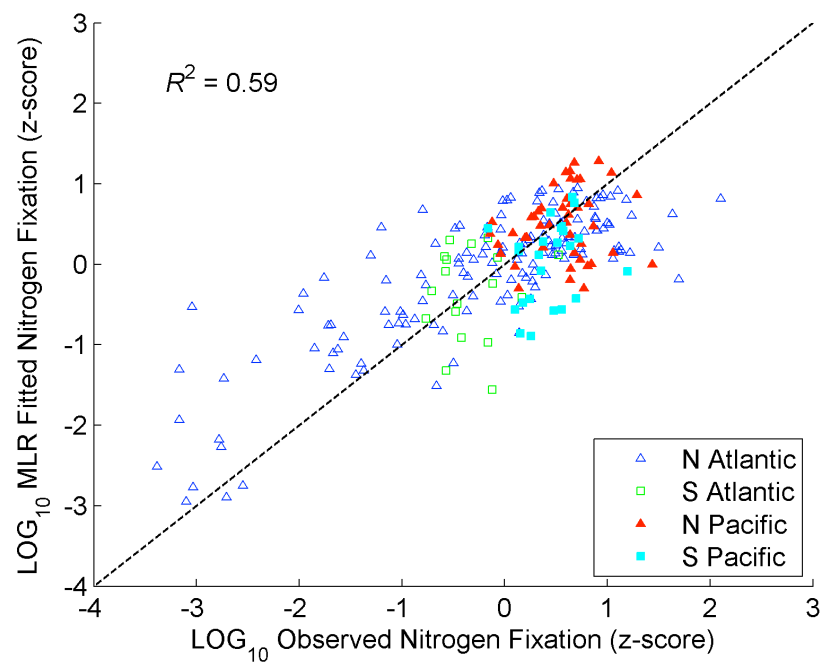

Fig. 5. Final multiple linear regression (MLR) results: observed nitrogen fixation versus MLR-fitted nitrogen fixation. Dashed line is a $1: 1$ line. Results were standardized ( $z$ scores).

37 (25-56) and $23(16-34) \mathrm{Tg} \mathrm{N} \mathrm{yr}^{-1}$ in the Atlantic, Pacific and Indian oceans, respectively (Table 6).

The environmental parameters included in the MLR model contributed to the estimated global marine NF differently. Minimum dissolved oxygen in upper $500 \mathrm{~m}$ contributed the most variance to the estimated global marine NF (Fig. 7a). It largely set the narrow latitudinal range of high NF in the Atlantic. The solar radiation limits the presence of the estimated NF to the range of $\sim 40^{\circ} \mathrm{S}$ to $40^{\circ} \mathrm{N}$ (Figs. $7 \mathrm{~b}$ ), as the annual average solar radiation outside this range (Fig. 2a) is mostly lower than the set limit of $180 \mathrm{~W} \mathrm{~m}^{-2}$ (Table 5). The average solar radiation in the mixed layer contributes high $\mathrm{NF}$ in the tropical upwelling zones (Fig. 7c). The upwelling in the eastern tropical Pacific led to high levels of surface nitrate, which limited the estimated NF in this region (Fig. 7d). The $\mathrm{P}^{*}$ variable favored $\mathrm{NF}$ in a vast region of the eastern Pacific (Fig. 7e). In the Atlantic, $\mathrm{P}^{*}$ also limited NF in the tropical and the northern subtropical regions while favoring (a)

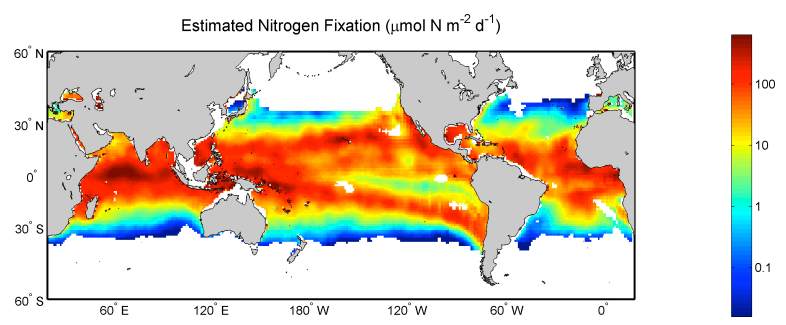

(b)

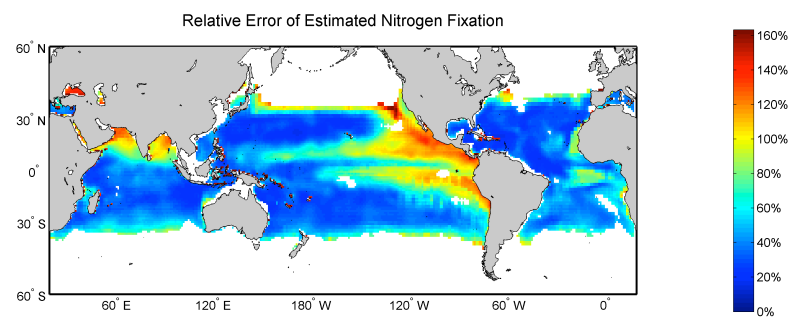

Fig. 6. (a) Map of estimated annual-mean, depth-integrated marine $\mathrm{N}_{2}$ fixation using equation derived from the multiple linear regression (MLR) and (b) the relative errors of the estimates. White areas were outside the limits of the environmental parameter(s) used in the regression or were less than $250 \mathrm{~m}$ depth in coastal zones.

it in the southern subtropical regions (Fig. 7e). Thus multiple environmental parameters contributed to the estimated NF in a region, often in an opposing fashion. For example, in the eastern tropical Pacific, the largest positive contributions by the average solar radiation in the mixed layer were only partially compensated for by negative contributions by nitrate. Surface nitrate may have acted as a suppressor in the MLR, which will be discussed later.

\section{Discussion}

\subsection{Environmental controls on marine nitrogen fixation}

In this study, we used several regression methods to assess hypothesized environmental controls on marine NF on 
(a)

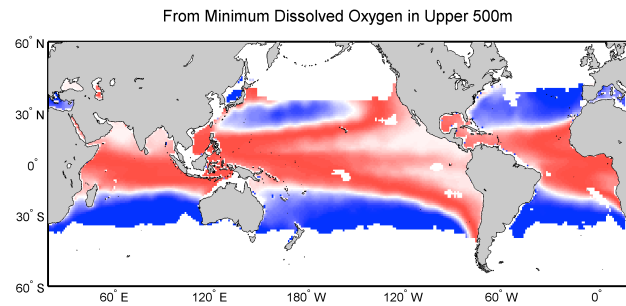

(b)

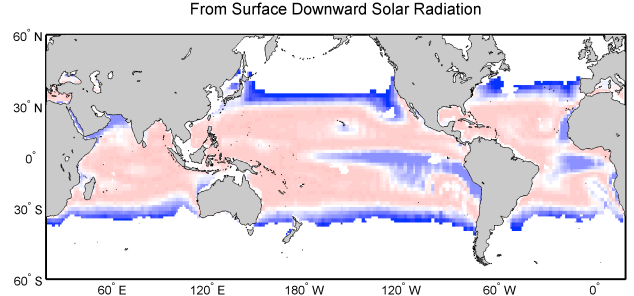

(c)

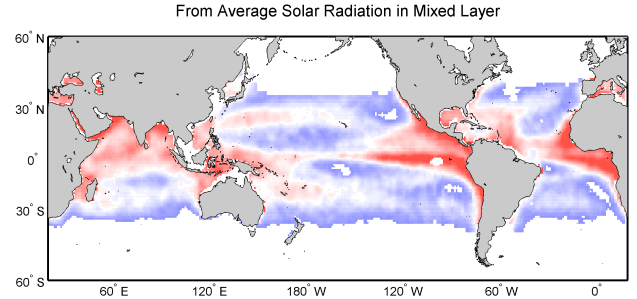

(d)

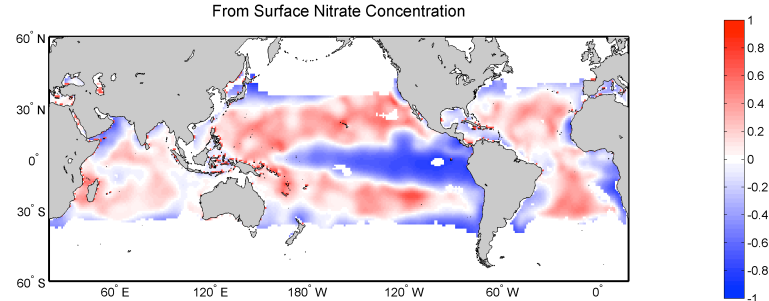

(e)

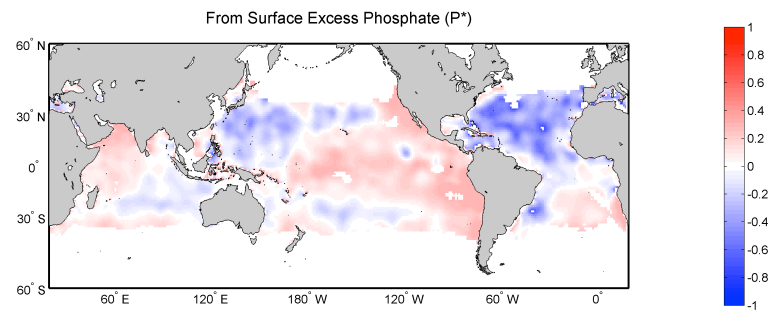

Fig. 7. Spatial anomalies of each component in the estimated logtransformed $\mathrm{N}_{2}$ fixation from environmental parameters (Eq. 4), including (a) minimum dissolved oxygen, (b) surface solar radiation, (c) average solar radiation in the mixed layer, (d) surface nitrate concentration and (e) excess phosphate $\left(\mathrm{P}^{*}\right)$. All the panels are plotted on same color scale. In each panel, the vast white areas, approximately north of $40^{\circ} \mathrm{N}$ and south of $40^{\circ} \mathrm{S}$, represent areas where the values of one or more environmental parameters were outside the limits for the MLR used to compute $\mathrm{N}_{2}$ fixation (see text for details).
Table 6. Comparison of estimated spatially integrated nitrogen fixation $\left(\mathrm{Tg} \mathrm{N} \mathrm{yr}^{-1}\right)$ in this study and in Luo et al. (2012)*.

\begin{tabular}{lll}
\hline Basin & This Study & Luo et al. (2012) \\
\hline North Atlantic Ocean & $9.1(6.7-12.6)$ & $1.7(1.3-2.2)$ \\
South Atlantic Ocean & $4.5(3.0-6.8)$ & $1.1(0.9-1.4)$ \\
North Pacific Ocean & $23(15-36)$ & $35(30-41)$ \\
South Pacific Ocean & $14(10-20)$ & $24(20-28)$ \\
Indian Ocean & $23(16-34)$ & - \\
Global Ocean & $74(51-110)$ & $62(52-73)$ \\
\hline
\end{tabular}

${ }^{*}$ Estimates in this study use the equation from the final multiple linear regression. Estimates in Luo et al. (2012) are spatially integrated nitrogen fixation estimated from geometric means of field data in every basin. Numbers in brackets are error ranges.

the global scale using a newly compiled database of field NF measurements. The samples covered the Pacific and Atlantic oceans, but unfortunately not the Indian Ocean. Annual climatologies of environmental parameters from different sources, mostly based on observations or modeled results validated by observations, were used in the regressions. Although we assessed multiple environmental parameters based on data availability, there could be other parameters that are currently unavailable but which could possibly also control marine NF, such as the fluxes of nitrate and phosphate and subsurface Fe. Recent laboratory studies, for example, suggest that NF rates of some marine microbial diazotrophs increase with rising aqueous $\mathrm{CO}_{2}$ concentration and that there are positive synergistic effects between elevated $\mathrm{CO}_{2}$ and warming (Hutchins et al., 2009).

Using the simple linear regressions, we computed the variance in the observed NF explained by each individual environmental parameter. The total variance explained by the MLR using all of the environmental parameters simultaneously may differ from the sum of the $R^{2}$ values from the simple, individual-parameter linear regressions, as correlations unavoidably exist among different environmental parameters (Table 2). Part or all of the explained variance by one environmental parameter may already be covered by its correlation with other environmental parameter(s) included in the regression. The stepwise MLR represented an effort to explain the maximum variance in the observed NF with the minimum number of predictors in the final regression equation as possible. An environmental parameter may be correlated with NF but absent from the stepwise MLR, indicating that the variance that could be contributed by this parameter has been fully covered by other parameter(s).

Surface solar radiation and minimum dissolved oxygen in the upper $500 \mathrm{~m}$ are likely the best available environmental predictors for the global spatial patterns of marine NF. These two parameters have the highest $R^{2}(\sim 40 \%)$ in the quadratic regressions (Table 1 ). They were also the first parameters added by the stepwise MLR, explaining $47 \%$ of the total variance even before the inclusion of the second-degree 
term for solar radiation (step 3 in Table 4). When the resulting MLR equation was used to map global spatial distributions, the minimum dissolved oxygen largely determined the patterns of marine NF, such as low rates in the subtropical Atlantic and high rates in the Pacific (Fig. 7a). The solar radiation mainly acted as a "mask" to limit the presence of NF to the tropical and subtropical regions. However, the MLR component from solar radiation is mostly saturated for NF in these regions (Fig. 7b) and thus does not contribute much variance.

It was interesting to find that the subsurface minimum dissolved oxygen was highly correlated with the observed NF. Although we initially included this environmental parameter to identify possible zones for denitrification, the results showed that the observed NF maintained relatively high rates when the minimum dissolved oxygen was lower than $\sim 150 \mu \mathrm{M}$, and decreased only when the minimum dissolved oxygen passed this threshold (Fig. 3e). As this threshold is far higher than the oxygen level in the OMZs, denitrification occurring in the OMZs appears not to influence the NF in the surface waters right above. Actually, in the regions without strong upwelling, surface waters may not have strong contact with waters at the depth of oxygen minimum. Denitrification may influence the NF downstream, which can be horizontally far away from the location where the denitrification occurred. If this is true, the signal of in situ $\mathrm{N}$-deficient waters, i.e., the $\mathrm{P}^{*}$, can still be found with high NF. However, the observed $\mathrm{NF}$ did not show strong correlation to the $\mathrm{P}^{*}$ concentration and the $\mathrm{P}^{*}$-convergence-estimated $\mathrm{NF}$, reaching low $R^{2}$ values of 0.07 and 0.11 from the quadratic regressions, respectively (Table 1; Fig. $3 \mathrm{~h}$ and i). On the global maps (Figs. $2 \mathrm{~h}$ and i), for instance, the $\mathrm{P}^{*}$ concentration and convergence are high in the subtropical South Atlantic, contrary to the low NF observed in the same basin (Fig. 1c). The highest NF was observed in the tropical Atlantic, while the $\mathrm{P}^{*}$ concentration is low in this region and the $\mathrm{P}^{*}$ convergence is comparable to those in the Pacific. Under current data availability, although the subsurface minimum dissolved oxygen is among the best predictors for the observed NF, there is no clear evidence that denitrification is a proximal control on spatial patterns of marine NF.

There could be other pathways whereby the subsurface low dissolved oxygen can stimulate marine NF. For instance, low $\mathrm{pH}$ is associated with low subsurface dissolved oxygen, as oxygen is consumed to decompose organic matter and to generate $\mathrm{CO}_{2}$ and carbonic acid. Selected laboratory experiments showed that reduced $\mathrm{pH} /$ elevated $\mathrm{CO}_{2}$ can increase NF (Hutchins et al., 2009), although field experiments did not show increased NF with elevated $\mathrm{CO}_{2}$ (Law et al., 2012). The high rate of organic matter remineralization in the OMZs may also produce Fe-binding ligands and prolong the residence time of dissolved Fe (Hunter and Boyd, 2007; Misumi et al., 2013; Misumi et al., 2011), which in turn could stimulate NF in the surface waters if bioavailable $\mathrm{Fe}$ in the surface ocean is mostly supplied from the subsurface ocean. This possibility might be partly supported by a large Fe plume recently found in the South Atlantic OMZ (Noble et al., 2012).

Average solar radiation in the mixed layer had a relatively high $R^{2}$ in the regressions with the observed NF (Table 1), and was also included by the stepwise MLR (Tables 3 and 4). This parameter combines both the surface solar radiation and the mixed layer depth, but mostly reflects the signals from the mixed layer depth, as shown by the high negative correlation of -0.91 between them (Table 2). The results support that marine NF tends to be active in stratified waters.

In the stepwise MLR, adding the first-degree nitrate term increased the explained variance by $4 \%$ (step 4 in Table 4 ), while in the simple linear regression nitrate explained only a low amount of variance, about $1 \%$ (Table 1). This showed that the surface nitrate acted as a suppressor for the MLR: it contributed to the explained variance indirectly by removing variance introduced by the minimum dissolved oxygen and the solar radiation. Although nitrate appears not to limit the $\mathrm{NF}$, there are other pools to supply fixed $\mathrm{N}$ to the ecosystem, such as ammonium and dissolved organic nitrogen (DON) (e.g., Karl et al., 1997). The map of bioavailable N may be different if these two pools of fixed $\mathrm{N}$ could be included in addition to the nitrate pool. Unfortunately, there is no global coverage of measurements for ammonium and DON (particularly the bioavailability of DON).

SST was not included in the MLR model, although the simple linear regression for SST showed a relatively high $R^{2}$ of 0.27 (Table 1). This was mainly because of the high correlation (0.74) between surface solar radiation and SST (Table 2). When the surface solar radiation and the average solar radiation in the mixed layer are removed from the predictor candidates, the stepwise MLR model includes the first- and second-degree terms of the SST and achieves a similar $R^{2}$ (Table 3). Because of the strong spatial correlation between SST and solar radiation, we cannot use regressions alone to determine the actual underlying mechanism. Distinguishing between the two environmental factors is not necessary for globally mapping NF, but discrimination at a process level becomes more relevant, for example, in attempts to project future changes in NF in response to climate change and SST warming (Boyd and Doney, 2002; Moore et al., 2013). While the surface solar radiation is not expected to change dramatically, projected surface warming could expand the zonal range of NF poleward and thus influence the global integral; a complete analysis, however, would also need to take into account other factors such as macro- and micronutrients and changes in subsurface oxygen.

$\mathrm{Fe}$ is a widely hypothesized environmental control on the spatial patterns of marine NF. In this study, we used dust deposition as a proxy for Fe supply. However, the study did not show that NF increased with dust deposition when it was included in the equations for either a simple linear regression or stepwise MLR against the global data set. There is some evidence from the observations for an increase in NF with dust deposition, at least regionally in the North Atlantic (Fig. 3j), 
but this does not appear to hold when lower dust deposition regions are included. Although the dust deposition data we used in this study are based on a model validated against limited observations (Luo et al., 2003; Mahowald et al., 2003), they capture at least the general patterns of observed deposition rates: higher in the Atlantic, (mainly because of dust from the Sahara), lower in the vast area of the Pacific (particularly the South Pacific) because it is remote from continents (Fig. 2i). Meanwhile, the observed NF was generally high in the Pacific, but low in the subtropical Atlantic (Fig. 1c). This result suggests that $\mathrm{NF}$ is saturated for $\mathrm{Fe}$ supply in most regions of the open ocean, diazotrophs have adapted to low $\mathrm{Fe}$ environment, or the $\mathrm{Fe}$ supplied from atmospheric dust deposition is mostly bio-unavailable and the bioavailable $\mathrm{Fe}$ in the surface ocean is mostly supplied via other processes. For example, low dissolved $\mathrm{Fe}$ concentration was found in the dust-rich South China Sea, hypothetically due to a lack of Fe-binding organic ligands (Wu et al., 2003). Another explanation is that the diazotrophic community in the Atlantic and Pacific oceans may be controlled by different environmental variables, and Fe limits NF in the Atlantic (Moore et al., 2009) (also see Fig. 3j). It was also found that upwelling events in the eastern equatorial Atlantic can increase NF rates in the surface waters by 2 to 7 times, suggesting the subsurface waters with a low $\mathrm{N}: \mathrm{P}$ ratio or that are rich in Fe are upwelled to support higher NF (Subramaniam et al., 2013). We suggest that more measurements for dissolved Fe, or even bioavailable $\mathrm{Fe}$ if possible, are needed in the future to test the Fe limitation on marine NF.

Our results show that atmospheric dust deposition does not appear to influence the spatial patterns of NF on global scale; this contradicts, to some extent, a number of recent global prognostic modeling studies that emphasize the role of $\mathrm{Fe}$ and atmospheric dust deposition in modulating marine NF (e.g., Moore and Doney, 2007; Moore et al., 2006). For example, the latitudinal extent of NF is similar in the simulations of Moore and Doney (2007) and the MLR-derived extrapolation, suggesting that the model variation in diazotroph growth rate with temperature captures either the observed correlation with solar radiation and/or SST. Regionally, both approaches agree on elevated NF in the Indian Ocean, however because of Fe limitation and other factors, the prognostic model predicts low values in the subtropical South Pacific and eastern subtropical/tropical Pacific, in disagreement with our data-derived mapped product. These differences between the modeled and data-based spatial patterns suggest that some prognostic models may overestimate the influence of Fe relative to nitrogen loss processes in OMZs.

\subsection{Uncertainties for regression and global estimate}

The $R^{2}$ of the stepwise MLR is 0.59 , meaning that there remains $41 \%$ of the variance in the observed NF that cannot be explained by annual mean climatologies of the environmental parameters. First we thought that using the annual clima- tologies might lower the explained variance. Thus we did experiments using monthly or seasonal climatologies matched to the sampling time of the observed NF, which, interestingly, resulted in substantially lower $R^{2}$ values in the simple linear regressions and the total explained variance was less than $40 \%$ in the stepwise MLR. This may suggest that the diazotrophs are selected to inhabit ocean regions with favorable long-term environmental conditions and fix $\mathrm{N}_{2}$ in relatively constant rates, instead of responding quickly to seasonal variability. Current available data are insufficient to identify seasonal variability of NF. More measurements are needed in the future, such as long-term measurements of marine NF in certain sites; these are currently almost entirely unavailable, except for monthly measurements taken since 2005 at Station ALOHA in the subtropical North Pacific (Church et al., 2009).

This study used a simplified model by assuming polynomial relationships between the NF and the environmental parameters (linear and up to quadratic terms). Data that were approximately log-normally distributed were also logtransformed. However, our MLR approach would not capture more nonlinear relationships between NF and environmental parameters. Regressions of nonlinear models with different predictors can be complex and are beyond the scope of this study, particularly when the form of the real relationships are poorly known.

Nevertheless, the MLR explained a substantial fraction of the variance in the observed NF and provided estimates of the uncertainties as a function of the included environmental parameters (Fig. 4). The uncertainties were reasonable in most conditions. When the MLR equation was applied to map global patterns and the uncertainties were propagated, high uncertainties occurred almost exclusively above the OMZ in the eastern tropical Pacific (Fig. 6b). This reflects the fact that we only have a few profiles of NF rate above major OMZs (Figs. 1, 2e and 4).

To estimate total NF in different ocean basins and in the global ocean, Luo et al. (2012) did not interpolate the NF data because of the limited spatial data coverage; they estimated the total NF by directly taking the geometric means of the data (Table 6). In this study, we used the same NF data, but also took advantage of the better coverage of the environmental parameters to construct a statistical model between NF and environmental parameters before estimating total NF (Table 6). Compared to Luo et al. (2012), this study estimated a comparable or slightly lower NF for the Pacific, and a significantly higher estimate for the Atlantic. The total $\mathrm{NF}$ in the Atlantic is still the lowest of all the basins and may yet be underestimated based on the negative regression biases at the highest observed NF values in the North Atlantic (Fig. 5).

The estimated globally integrated NF from this study, 74 (error range: $51-110) \mathrm{Tg} \mathrm{N} \mathrm{yr}^{-1}$, is at the low end of current geochemical estimates of $\sim 100-200 \mathrm{Tg} \mathrm{N} \mathrm{yr}^{-1}$ (Eugster and Gruber, 2012; Galloway et al., 2004; Gruber, 2008). As most 
of the original NF data used in this study were measured using ${ }^{15} \mathrm{~N}_{2}$ method, this global estimate probably represents the rate of net NF (gross NF minus release of newly fixed N). As discussed above, the flaw of the previous ${ }^{15} \mathrm{~N}_{2}$ method may also have substantially underestimated the NF. Our estimates are based on the data from the open ocean, although NF can be substantial in coastal regions (Mulholland et al., 2012). We also assumed that the samples used in this study covered all possible environmental conditions for effective NF and thus limited the estimated NF to the tropical and subtropical regions. However, a recent study found substantial $\mathrm{NF}$ ranging from 0.02 to $4.5 \mu \mathrm{mol} \mathrm{N} \mathrm{m} \mathrm{N}^{-3} \mathrm{~d}^{-1}$ in the surface Canadian Arctic (Blais et al., 2012). These samples were not included in this study because their sampling environmental conditions were very different from the other samples, and also they were not depth-integrated samples. But these samples suggest marine NF can occur in higher latitudes, which would increase the current estimates of global marine NF. With these considerations, we should expect a higher global marine NF than the estimate provided by this study.

\section{Conclusions}

This data-based study assessed different environmental controls on global marine $\mathrm{N}_{2}$ fixation (NF) using simple and multiple linear regressions. The results suggested that marine pelagic NF is controlled by either solar radiation or temperature and is largely restricted to the warm, stratified, high solar radiation bands in the tropics and subtropics. We further identified that marine pelagic NF can be low in the regions with high subsurface dissolved oxygen, although the controlling mechanism is unclear. Our data are not sufficient to support the hypothesis that marine NF is controlled by denitrification and the subsequent supply of N-deficit waters. Although it is possible that other environmental parameters such as atmospheric dust deposition (presumably representing Fe supply) and wind speed can influence marine NF over regional scales, on the global scale they were not identified by our study to explain substantial variance in the observed spatial patterns in marine NF. Applying the multiple linear regression equation and related global coverage of environmental controls, we estimated the global NF to be $\sim 50-100 \mathrm{Tg} \mathrm{Nyr}^{-1}$, a value at the lower end of current geochemical estimates. It was likely that we underestimated the global NF, both because we excluded NF in higher latitudes, and also because most of the NF rates used in this study were likely underestimated by using the method without fully equilibrated ${ }^{15} \mathrm{~N}_{2}$ gas.

Studies of field data suggest that subsurface oxygen minimum zones (OMZs) have been expanding in the tropical Pacific and other areas because of decreasing oxygen solubility as a consequence of global warming and weak ventilation resulting from enhanced stratification (Stramma et al., 2008). If the trend of deoxygenation continues, marine NF may in- crease if our finding that high subsurface dissolved oxygen can limit NF in the above waters is robust. How much the marine NF can increase is still a question, as NF is ultimately limited by multiple environmental variables such as solar radiation and mixed layer depth, as has been demonstrated by this study. Even though our study does not indicate that $\mathrm{Fe}$ and other nutrients are affecting NF patterns in the contemporary ocean, they could become limiting in the future if NF were to increase in concert with the $\mathrm{N}$ loss. As the stratification develops with global warming, the supply of nutrients from deep waters can decrease and $\mathrm{Fe}$, phosphorus and vitamins may act even more quickly to limit elevated NF (Moore et al., 2013). Mechanistic studies are also needed to better distinguish between temperature and solar radiation controls on the zonal extent of NF.

The spatial coverage of NF observations in the MAREDAT database currently are limited in the Pacific and even more in the Indian Ocean. Our findings need to be assessed with more extensive spatial sampling in these two important ocean basins. Particularly, there were very few samples of $\mathrm{NF}$ above the major OMZs, such as the eastern tropical Pacific, eastern tropical Atlantic and the northern Indian Ocean, which resulted in large uncertainties in our estimated NF in these areas. Scientists tended to sample ocean regions that were believed to be inhabited by diazotrophs. Our study, however, showed some regions that can be NF "hot" zones that have not been well sampled. We suggest that a top priority for future field sampling should include measurements of marine NF within and downstream of OMZs, and then in the other areas of the Pacific and Indian oceans. Scientists should also pursue better sampling of bioavailable $\mathrm{Fe}$, as well as $\mathrm{P}^{*}$, through measurements of both inorganic and organic fixed $\mathrm{N}$ and $\mathrm{P}$.

\section{Supplementary material related to this article is available online at http://www.biogeosciences.net/11/691/ 2014/bg-11-691-2014-supplement.pdf.}

Acknowledgements. This project was supported by the NSF Center for Microbial Oceanography: Research and Education (C-MORE) (EF-0424599), an NSF Emerging Topics in Biogeochemical Cycles grant (ETBC, AGS-1020594), and the Gordon and Betty Moore Foundation. NCEP Reanalysis data were provided by the NOAA/OAR/ESRL PSD, Boulder, Colorado, USA. Chlorophyll data were provided by SeaWiFS Project and the Ocean Biology Processing Group (OBPG) at the NASA, Goddard Space Flight Center, Greenbelt, MD, USA. We thank all the scientists and crews involved in collecting field samples used in this study. We thank Nicolas Gruber and another anonymous reviewer for their thorough and constructive comments, which greatly improved the quality of this work. Dennis McGillicuddy Jr and Larry Anderson are also thanked for their useful comments to the paper.

Edited by: L. Bopp 


\section{References}

Berman-Frank, I., Cullen, J. T., Shaked, Y., Sherrell, R. M., and Falkowski, P. G.: Iron availability, cellular iron quotas, and nitrogen fixation in Trichodesmium, Limnol. Oceanogr., 46, 12491260, doi:10.4319/lo.2001.46.6.1249, 2001.

Blais, M., Tremblay, J.-É., Jungblut, A. D., Gagnon, J., Martin, J., Thaler, M., and Lovejoy, C.: Nitrogen fixation and identification of potential diazotrophs in the Canadian Arctic, Global Biogeochem. Cy., 26, GB3022, doi:10.1029/2011gb004096, 2012.

Boyd, P. W. and Doney, S. C.: Modelling regional responses by marine pelagic ecosystems to global climate change, Geophys. Res. Lett., 29, 1806, doi:10.1029/2001g1014130, 2002.

Buitenhuis, E. T., Vogt, M., Moriarty, R., Bednaršek, N., Doney, S. C., Leblanc, K., Le Quéré, C., Luo, Y. W., O’Brien, C., O’Brien, T., Peloquin, J., Schiebel, R., and Swan, C.: MAREDAT: towards a world atlas of MARine Ecosystem DATa, Earth Syst. Sci. Data, 5, 227-239, doi:10.5194/essd-5-227-2013, 2013.

Carpenter, E. J.: Nitrogen fixation by marine Oscillatoria (Trichodesmium) in the world's oceans, in: Nitrogen in the Marine Environment, edited by: Carpenter, E. J. and Capone, D. G., Academic Press, New York, 1983a.

Carpenter, E. J.: Physiology and ecology of marine planktonic Oscillatoria (Trichodesmium), Mar. Biol. Lett., 4, 69-85, $1983 \mathrm{~b}$.

Carpenter, E. J. and Capone, D. G.: Significance of Trichodesmium blooms in the marine nitrogen cycle, in: Marine Pelagic Cyanobacteria: Trichodesmium and other Diazotrophs, edited by: Carpenter, E. J., Capone, D. G., and Rueter, J. G., Kluwer Academic Publishers, Dordrecht, 1992.

Carpenter, E. J. and Capone, D. G.: Nitrogen fixation in the marine environment, in: Nitrogen in the Marine Environment, 2nd edition, edited by: Capone, D. G., Bronk, D. A., Mulholland, M. R., and Carpenter, E. J., Academic Press, London, 2008.

Carr, N. G. and Whitton, B. A.: The Biology of Cyanobacteria, Univ. of California Press, 1982.

Church, M. J., Mahaffey, C., Letelier, R. M., Lukas, R., Zehr, J. P., and Karl, D. M.: Physical forcing of nitrogen fixation and diazotroph community structure in the North $\mathrm{Pa}-$ cific subtropical gyre, Global Biogeochem. Cy., 23, GB2020, doi:10.1029/2008gb003418, 2009.

Cook, R. D.: Detection of influential observation in linear regression, Technometrics, 19, 15-18, doi:10.2307/1268249, 1977.

Cullen, J. J.: Hypotheses to explain high-nutrient conditions in the open sea, Limnol. Oceanogr., 36, 1578-1599, 1991.

de Boyer Montégut, C., Madec, G., Fischer, A. S., Lazar, A., and Iudicone, D.: Mixed layer depth over the global ocean: An examination of profile data and a profile-based climatology, J. Geophys. Res.-Oceans, 109, C12003, doi:10.1029/2004jc002378, 2004.

Deutsch, C., Sarmiento, J. L., Sigman, D. M., Gruber, N., and Dunne, J. P.: Spatial coupling of nitrogen inputs and losses in the ocean, Nature, 445, 163-167, doi:10.1038/nature05392, 2007.

Doney, S. C., Lima, I., Moore, J. K., Lindsay, K., Behrenfeld, M. J., Westberry, T. K., Mahowald, N., Glover, D. M., and Takahashi, T.: Skill metrics for confronting global upper ocean ecosystembiogeochemistry models against field and remote sensing data, J. Mar. Syst., 76, 95-112, doi:10.1016/j.jmarsys.2008.05.015, 2009.

Draper, N. R. and Smith, H.: Applied Regression Analysis, WileyInterscience, Hoboken, NJ, 1998.
Dutkiewicz, S., Ward, B. A., Monteiro, F., and Follows, M. J.: Interconnection of nitrogen fixers and iron in the Pacific Ocean: Theory and numerical simulations, Global Biogeochem. Cy., 26, GB1012, doi:10.1029/2011GB004039, 2012.

Eugster, O. and Gruber, N.: A probabilistic estimate of global marine N-fixation and denitrification, Global Biogeochem. Cy., 26, GB4013, doi:10.1029/2012gb004300, 2012.

Fernández, A., Mouriño-Carballido, B., Bode, A., Varela, M., and Marañón, E.: Latitudinal distribution of Trichodesmium spp. and $\mathrm{N}_{2}$ fixation in the Atlantic Ocean, Biogeosciences, 7, 31673176, doi:10.5194/bg-7-3167-2010, 2010.

Gallon, J. R.: $\mathrm{N}_{2}$ fixation in phototrophs: adaptation to a specialized way of life, Plant Soil, 230, 39-48, doi:10.1023/A:1004640219659, 2001.

Galloway, J. N., Dentener, F. J., Capone, D. G., Boyer, E. W., Howarth, R. W., Seitzinger, S. P., Asner, G. P., Cleveland, C. C., Green, P. A., Holland, E. A., Karl, D. M., Michaels, A. F., Porter, J. H., Townsend, A. R., and Vorosmarty, C. J.: Nitrogen cycles: past, present, and future, Biogeochemistry, 70, 153-226, doi:10.1007/s10533-004-0370-0, 2004.

Garcia, H. E., Locarnini, R. A., Boyer, T. P., Antonov, J. I., Baranova, O. K., Zweng, M. M., and Johnson, D. R.: World Ocean Atlas 2009, Volume 3: dissolved oxygen, apparent oxygen utilization, and oxygen saturation, in: NOAA Atlas NESDIS 70, edited by: Levitus, S., US Government Printing Office, Washington, DC, 2010a.

Garcia, H. E., Locarnini, R. A., Boyer, T. P., Antonov, J. I., Zweng, M. M., Baranova, O. K., and Johnson, D. R.: World Ocean Atlas 2009, Volume 4: nutrients (phosphate, nitrate, silicate), in: NOAA Atlas NESDIS 71, edited by: Levitus, S., US Government Printing Office, Washington, DC, $2010 \mathrm{~b}$.

Glover, D. M., Jenkins, W. J., and Doney, S. C.: Modeling Methods for Marine Science, Cambridge University Press, Cambridge, UK, 2011.

Grabowski, M. N. W., Church, M. J., and Karl, D. M.: Nitrogen fixation rates and controls at Stn ALOHA, Aquat. Microb. Ecol., 52, 175-183, doi:10.3354/Ame01209, 2008.

Großkopf, T., Mohr, W., Baustian, T., Schunck, H., Gill, D., Kuypers, M. M. M., Lavik, G., Schmitz, R. A., Wallace, D. W. R., and LaRoche, J.: Doubling of marine dinitrogen-fixation rates based on direct measurements, Nature, 488, 361-364, doi:10.1038/nature11338, 2012.

Gruber, N.: The marine nitrogen cycle: overview and challenges, in: Nitrogen in the marine environment, 2nd edition, edited by: Capone, D. G., Bronk, D. A., Mulholland, M. R., and Carpenter, E. J., Elsevier, Amsterdam, 2008.

Halm, H., Lam, P., Ferdelman, T. G., Lavik, G., Dittmar, T., LaRoche, J., D’Hondt, S., and Kuypers, M. M. M.: Heterotrophic organisms dominate nitrogen fixation in the South Pacific Gyre, ISME J., 6, 1238-1249, doi:10.1038/ismej.2011.182, 2012.

Howard, J. B. and Rees, D. C.: Structural basis of biological nitrogen fixation, Chem. Rev., 96, 2965-2982, doi:10.1021/cr9500545, 1996.

Hunter, K. A. and Boyd, P. W.: Iron-binding ligands and their role in the ocean biogeochemistry of iron, Environ. Chem., 4, 221-232, doi:10.1071/En07012, 2007.

Hutchins, D. A., Mulholland, M. R., and Fu, F.: Nutrient cycles and marine microbes in a $\mathrm{CO}_{2}$-enriched ocean, Oceanography, 22, 128-145, doi:10.5670/oceanog.2009.103, 2009. 
Kalnay, E., Kanamitsu, M., Kistler, R., Collins, W., Deaven, D., Gandin, L., Iredell, M., Saha, S., White, G., Woollen, J., Zhu, Y., Chelliah, M., Ebisuzaki, W., Higgins, W., Janowiak, J., Mo, K. C., Ropelewski, C., Wang, J., Leetmaa, A., Reynolds, R., Jenne, R., and Joseph, D.: The NCEP/NCAR 40-year reanalysis project, B. Am. Meteorol. Soc., 77, 437-471, doi:10.1175/15200477(1996)077<0437:TNYRP>2.0.CO;2, 1996.

Karl, D., Michaels, A., Bergman, B., Capone, D., Carpenter, E., Letelier, R., Lipschultz, F., Paerl, H., Sigman, D., and Stal, L.: Dinitrogen fixation in the world's oceans, Biogeochemistry, 57/58, 47-98, doi:10.1023/A:1015798105851, 2002.

Karl, D. M. and Letelier, R. M.: Nitrogen fixation-enhanced carbon sequestration in low nitrate, low chlorophyll seascapes, Mar. Ecol.-Prog. Ser., 364, 257-268, doi:10.3354/Meps07547, 2008.

Karl, D. M., Letelier, R., Tupas, L., Dore, J., Christian, J., and Hebel, D.: The role of nitrogen fixation in biogeochemical cycling in the subtropical North Pacific Ocean, Nature, 388, 533538, 1997

Karl, D. M., Bidigare, R. R., and Letelier, R. M.: Long-term changes in plankton community structure and productivity in the North Pacific Subtropical Gyre: The domain shift hypothesis, DeepSea Res. II, 48, 1449-1470, doi:10.1016/S0967-0645(00)001491, 2001.

Karl, D. M., Bidigare, R. R., Church, M. J., Dore, J. E., Letelier, R. M., Mahaffey, C., and Zehr, J. P.: The nitrogen cycle in the North Pacific trades biome: an evolving paradigm, in: Nitrogen in the marine environment, 2nd edition, edited by: Capone, D. G., Bronk, D. A., Mulholland, M. R., and Carpenter, E. J., Elsevier, Amsterdam, 2008.

Kustka, A. B., Sanudo-Wilhelmy, S. A., Carpenter, E. J., Capone, D. G., Burns, J., and Sunda, W. G.: Iron requirements for dinitrogen- and ammonium-supported growth in cultures of Trichodesmium (IMS 101): Comparsion with nitrogen fixation rates and iron:carbon ratios of field populations, Limnol. Oceanogr., 48, 1869-1884, doi:10.4319/lo.2003.48.5.1869, 2003.

Lam, P. and Kuypers, M. M. M.: Microbial nitrogen cycling processes in oxygen minimum zones, Annu. Rev. Mar. Sci., 3, $317-$ 345, doi:10.1146/annurev-marine-120709-142814, 2011.

Law, C. S., Breitbarth, E., Hoffmann, L. J., McGraw, C. M., Langlois, R. J., LaRoche, J., Marriner, A., and Safi, K. A.: No stimulation of nitrogen fixation by non-filamentous diazotrophs under elevated $\mathrm{CO}_{2}$ in the South Pacific, Glob. Change Biol., 18, 30043014, doi:10.1111/j.1365-2486.2012.02777.x, 2012.

Locarnini, R. A., Mishonov, A. V., Antonov, J. I., Boyer, T. P., Garcia, H. E., Baranova, O. K., Zweng, M. M., and Johnson, D. R.: World Ocean Atlas 2009, Volume 1: temperature, in: NOAA Atlas NESDIS 68, edited by: Levitus, S., US Government Printing Office, Washington, DC, 2010.

Luo, C., Mahowald, N. M., and del Corral, J.: Sensitivity study of meteorological parameters on mineral aerosol mobilization, transport, and distribution, J. Geophys. Res.-Atmos., 108, 4447, doi:10.1029/2003jd003483, 2003.

Luo, Y.-W., Doney, S. C., Anderson, L. A., Benavides, M., BermanFrank, I., Bode, A., Bonnet, S., Boström, K. H., Böttjer, D., Capone, D. G., Carpenter, E. J., Chen, Y. L., Church, M. J., Dore, J. E., Falcón, L. I., Fernández, A., Foster, R. A., Furuya, K., Gómez, F., Gundersen, K., Hynes, A. M., Karl, D. M., Kitajima, S., Langlois, R. J., LaRoche, J., Letelier, R. M., Marañón, E., McGillicuddy Jr, D. J., Moisander, P. H., Moore, C. M.,
Mouriño-Carballido, B., Mulholland, M. R., Needoba, J. A., Orcutt, K. M., Poulton, A. J., Rahav, E., Raimbault, P., Rees, A. P., Riemann, L., Shiozaki, T., Subramaniam, A., Tyrrell, T., TurkKubo, K. A., Varela, M., Villareal, T. A., Webb, E. A., White, A. E., Wu, J., and Zehr, J. P.: Database of diazotrophs in global ocean: abundance, biomass and nitrogen fixation rates, Earth Syst. Sci. Data, 4, 47-73, doi:10.5194/essd-4-47-2012, 2012.

Mahowald, N., Luo, C., del Corral, J., and Zender, C. S.: Interannual variability in atmospheric mineral aerosols from a 22 -year model simulation and observational data, J. Geophys. Res.-Atmos., 108, 4352, doi:10.1029/2002jd002821, 2003.

Martiny, A. C., Pham, C. T. A., Primeau, F. W., Vrugt, J. A., Moore, J. K., Levin, S. A., and Lomas, M. W.: Strong latitudinal patterns in the elemental ratios of marine plankton and organic matter, Nat. Geosci., 6, 279-283, doi:10.1038/ngeo1757, 2013.

Mills, M. M., Ridame, C., Davey, M., La Roche, J., and Geider, R. J.: Iron and phosphorus co-limit nitrogen fixation in the eastern tropical North Atlantic, Nature, 429, 292-294, doi:10.1038/nature02550, 2004.

Misumi, K., Tsumune, D., Yoshida, Y., Uchimoto, K., Nakamura, T., Nishioka, J., Mitsudera, H., Bryan, F. O., Lindsay, K., Moore, J. K., and Doney, S. C.: Mechanisms controlling dissolved iron distribution in the North Pacific: A model study, J. Geophys Res.-Biogeo., 116, G03005, doi:10.1029/2010jg001541, 2011.

Misumi, K., Lindsay, K., Moore, J. K., Doney, S. C., Tsumune, D., and Yoshida, Y.: Humic substances may control dissolved iron distributions in the global ocean: Implications from numerical simulations, Global Biogeochem. Cy., 27, 450-462, doi:10.1002/gbc.20039, 2013.

Mohr, W., Grosskopf, T., Wallace, D. W. R., and LaRoche, J.: Methodological underestimation of oceanic nitrogen fixation rates, PLoS One, 5, e12583, doi:10.1371/journal.pone.0012583, 2010.

Moore, C. M., Mills, M. M., Achterberg, E. P., Geider, R. J., LaRoche, J., Lucas, M. I., McDonagh, E. L., Pan, X., Poulton, A. J., Rijkenberg, M. J. A., Suggett, D. J., Ussher, S. J., and Woodward, E. M. S.: Large-scale distribution of Atlantic nitrogen fixation controlled by iron availability, Nat. Geosci., 2, 867-871, doi:10.1038/ngeo667, 2009.

Moore, J. K. and Doney, S. C.: Iron availability limits the ocean nitrogen inventory stabilizing feedbacks between marine denitrification and nitrogen fixation, Global Biogeochem. Cy., 21, GB2001, doi:10.1029/2006gb002762, 2007.

Moore, J. K., Doney, S. C., Lindsay, K., Mahowald, N., and Michaels, A. F.: Nitrogen fixation amplifies the ocean biogeochemical response to decadal timescale variations in mineral dust deposition, Tellus B, 58, 560-572, doi:10.1111/j.16000889.2006.00209.x, 2006.

Moore, J. K., Lindsay, K., Doney, S. C., Long, M. C., and Misumi, K.: Marine Ecosystem Dynamics and Biogeochemical Cycling in the Community Earth System Model [CESM1(BGC)]: Comparison of the 1990s with the 2090s under the RCP4.5 and RCP8.5 Scenarios, J. Climate, 26, 9291-9312, doi:10.1175/JCLI-D-1200566.1, 2013.

Morel, A.: Optical modelling of the upper ocean in relation to its biogenous matter content (Case 1 waters), J. Geophys. Res., 93, 10749-10768, 1988.

Moutin, T., Karl, D. M., Duhamel, S., Rimmelin, P., Raimbault, P., Van Mooy, B. A. S., and Claustre, H.: Phosphate availability 
and the ultimate control of new nitrogen input by nitrogen fixation in the tropical Pacific Ocean, Biogeosciences, 5, 95-109, doi:10.5194/bg-5-95-2008, 2008.

Mulholland, M. R.: The fate of nitrogen fixed by diazotrophs in the ocean, Biogeosciences, 4, 37-51, doi:10.5194/bg-4-37-2007, 2007.

Mulholland, M. R., Bronk, D. A., and Capone, D. G.: Dinitrogen fixation and release of ammonium and dissolved organic nitrogen by Trichodesmium IMS101, Aquat. Microb. Ecol., 37, 8594, doi:10.3354/ame037085, 2004.

Mulholland, M. R., Bernhardt, P. W., Blanco-Garcia, J. L., Mannino, A., Hyde, K., Mondragon, E., Turk, K., Moisander, P. H., and Zehr, J. P.: Rates of dinitrogen fixation and the abundance of diazotrophs in North American coastal waters between Cape Hatteras and Georges Bank, Limnol. Oceanogr., 57, 1067-1083, doi:10.4319/lo.2012.57.4.1067, 2012.

Noble, A. E., Lamborg, C. H., Ohnemus, D. C., Lam, P. J., Goepfert, T. J., Measures, C. I., Frame, C. H., Casciotti, K. L., DiTullio, G. R., Jennings, J., and Saito, M. A.: Basin-scale inputs of cobalt, iron, and manganese from the Benguela-Angola front to the South Atlantic Ocean, Limnol. Oceanogr., 57, 989-1010, doi:10.4319/lo.2012.57.4.0989, 2012.

Sañudo-Wilhelmy, S. A., Kustka, A. B., Gobler, C. J., Hutchins, D. A., Yang, M., Lwiza, K., Burns, J., Capone, D. G., Raven, J. A., and Carpenter, E. J.: Phosphorus limitation of nitrogen fixation by Trichodesmium in the central Atlantic Ocean, Nature, 411, 66-69, doi:10.1038/35075041, 2001.
Sohm, J. A., Webb, E. A., and Capone, D. G.: Emerging patterns of marine nitrogen fixation, Nat. Rev. Microbiol., 9, 499-508, doi:10.1038/nrmicro2594, 2011.

Staal, M., Meysman, F. J. R., and Stal, L. J.: Temperature excludes $\mathrm{N}_{2}$-fixing heterocystous cyanobacteria in the tropical oceans, Nature, 425, 504-507, doi:10.1038/Nature01999, 2003.

Stramma, L., Johnson, G. C., Sprintall, J., and Mohrholz, V.: Expanding oxygen-minimum zones in the tropical oceans, Science, 320, 655-658, doi:10.1126/science.1153847, 2008.

Subramaniam, A., Mahaffey, C., Johns, W., and Mahowald, N.: Equatorial upwelling enhances nitrogen fixation in the Atlantic Ocean, Geophys. Res. Lett., 40, 1766-1771, doi:10.1002/grl.50250, 2013.

Watkins-Brandt, K. S., Letelier, R. M., Spitz, Y. H., Church, M. J., Böttjer, D., and White, A. E.: Addition of inorganic or organic phosphorus enhances nitrogen and carbon fixation in the oligotrophic North Pacific, Mar. Ecol.-Prog. Ser., 432, 17-29, doi:10.3354/meps09147, 2011.

Wilson, S. T., Böttjer, D., Church, M. J., and Karl, D. M.: Comparative assessment of nitrogen fixation methodologies conducted in the oligotrophic North Pacific Ocean, Appl. Environm. Microbiol., 78, 6516-6523, doi:10.1128/AEM.01146-12, 2012.

Wu, J. F., Chung, S. W., Wen, L. S., Liu, K. K., Chen, Y. L. L., Chen, H. Y., and Karl, D. M.: Dissolved inorganic phosphorus, dissolved iron, and Trichodesmium in the oligotrophic South China Sea, Global Biogeochem. Cy., 17, 1008, doi:10.1029/2002gb001924, 2003. 